\title{
Functions of EpCAM in physiological processes and diseases (Review)
}

\author{
LI HUANG $^{1-3^{*}}$, YANHONG YANG ${ }^{4 *}$, FEI YANG ${ }^{1-3}$, SHAOMIN LIU ${ }^{1-3}$, \\ ZIQIN ZHU ${ }^{1,4}$, ZILI LEI $^{1,2}$ and JIAO GUO ${ }^{1,2}$ \\ ${ }^{1}$ Guangdong Metabolic Disease Research Center of Integrated Chinese and Western Medicine, \\ ${ }^{2}$ Institute of Chinese Medicinal Sciences and ${ }^{3}$ School of Traditional Chinese Medicine, Guangdong Pharmaceutical University, \\ Guangzhou Higher Education Mega Center, Guangzhou, Guangdong 510006; ${ }^{4}$ The First Affiliated Hospital, \\ School of Clinical Medicine, Guangdong Pharmaceutical University, Guangzhou, Guangdong 510080, P.R. China
}

Received March 25, 2018; Accepted July 4, 2018

DOI: $10.3892 /$ ijmm.2018.3764

\begin{abstract}
EpCAM (epithelial cell adhesion molecule) is a type I transmembrane glycoprotein, which was originally identified as a tumor-associated antigen due to its high expression level in rapidly growing epithelial tumors. Germ line mutations of the human EpCAM gene have been indicated as the cause of congenital tufting enteropathy. Previous studies based on cell models have revealed that EpCAM contributes to various biological processes including cell adhesion, signaling, migration and proliferation. Due to the previous lack of genetic animal models, the in vivo functions of EpCAM remain largely unknown. However, EpCAM genetic animal models have recently been generated, and are useful for understanding the functions of EpCAM. The authors here briefly review the functions and mechanisms of EpCAM in physiological processes and different diseases.
\end{abstract}

\section{Contents}

1. Introduction

2. Expression pattern and subcellular localization of EpCAM

3. Functions of EpCAM in physiological processes

4. Functions of EpCAM in development and stem cells

5. Functions of EpCAM in diseases

6. Conclusions and perspectives

Correspondence to: Dr Zili Lei or Dr Jiao Guo, Institute of Chinese Medicinal Sciences, Guangdong Pharmaceutical University, Guangzhou Higher Education Mega Center, 280 Waihuan East Road, Center, Panyu, Guangzhou, Guangdong 510006, P.R. China E-mail: 3182683090@qq.com

E-mail: gyguoyz@163.com

*Contributed equally

Key words: epithelial cell adhesion molecule, cell-cell junctions, stem cell, cancer, congenital tufting enteropathy

\section{Introduction}

The epithelial cell adhesion molecule (EpCAM, also known as cluster of differentiation 326 or Tacstd1), is a 40 KD transmembrane glycoprotein, consisting of 314 amino acids, firstly identified in colon cancer in 1979. Its molecular structure includes: Extracellular domain (EpEX), single transmembrane domain and intracellular domain (EpICD) (1). EpCAM is a homophilic $\mathrm{Ca}^{2+}$-independent cell-cell adhesion molecule. In addition to a role in intercellular adhesion, in vitro and in vivo studies have revealed that EpCAM plays important roles in cell signaling, proliferation, differentiation, formation and maintenance of organ morphology (2).

EpCAM is expressed in many kinds of epithelial tissues (3) and is also a cell surface marker on various stem and progenitor cells $(4,5)$. Mutations in human EpCAM have been identified to be associated with congenital tufting enteropathy (CTE) (6). To investigate the in vivo functions of EpCAM, several mutant animal models have been generated in recent years, including mice, zebrafish and Xenopus. At least 4 types of global EpCAM knockout mice suggest that the phenotype is similar to the symptoms of human CTE (7-9), however one model leads to embryonic lethality due to placental defect (10). In addition, a conditional knockout mouse model exhibits impaired motility of the skin Langerhans cells (11). Zebrafish (12) and Xenopus $(13,14)$ models demonstrate the functions of EpCAM in morphogenic movements during gastrulation. Hepatic development has also been affected in EpCAM mutant zebrafish (15). These studies have confirmed the important functions of EpCAM in physiological processes and development.

In addition to important roles in developmental processes, EpCAM is also highly expressed in epithelial tumor tissues, and promotes the proliferation of tumors $(16,17)$. Its functions in oncogenesis and cancer cells have been studied by many groups, and therapeutic approaches targeting EpCAM are also currently being developed.

Here, the authors summarize the functions of EpCAM in physiology, development and diseases, and review current progresses in identifying the underlying molecular mechanisms. 


\section{Expression pattern and subcellular localization of EрCAM}

EpCAM can be detected in many tissues from very early embryos to adult animals and human beings, and it is also highly expressed in numerous types of tumor tissue.

Expression of EpCAM during embryo development. EpCAM mRNA can be detected in the fertilized zygotes of zebrafish (12), indicating it is present maternally. In 1981, EpCAM was defined as one of the human trophoblast cell-surface antigens (18). In the developing mouse embryo, EpCAM is also detected in the inner cell mass of the blastocyst (7), the epiblast $(7,19)$, and the gonads at E12.5 (7). At early gastrulation stages including E6.5 and E7.5, EpCAM is expressed in the ectoderm and endoderm, however may be used as a marker of the endoderm at and after E8.25 (19). Nagao et al (10) revealed that the expression of EpCAM is most prominent in the facial primordia, gut, branchial arches, and otocyst at E9.5. EpCAM protein may be detected in the allantois, the labyrinthine layer, and the spongiotrophoblasts from E8.5 and E9.5 placentas of mice, however the highest expression levels are detected in the labyrinth. In addition, the expression of EpCAM is readily detected in various epithelial components of a variety of organs including hair follicles, the nasal plexus, lungs, kidneys, and pancreas examined at E14.5 (10). EpCAM mRNA is detected in the developing gut of mice from E9.5 to E15.5, as well as throughout the intestine, from the duodenum to the colon, at E18.5 (7). EpCAM protein is detected in the villi and intervillus domains, and is localized to cell-cell junctions of the intestinal epithelium at E18.5 and at P0. EpCAM is highly expressed in the epithelia of stomach, lungs, pancreas, and kidneys at E18.5 (7). During the embryogenesis of zebrafish, maternally provided EpCAM mRNA is uniformly distributed in all cells of cleavage and early blastula stage embryos. Following the onset of epiboly, EpCAM mRNA is restricted to the enveloping layer (EVL) and basal epidermis, indicating the zygotic expression of EpCAM is restricted to the epithelial structures (12). EpCAM has also been demonstrated to be expressed in migrating neuromast primordia, otic vesicles and olfactory placodes (12).

Expression pattern of EpCAM in adult organs and tumor tissues. EpCAM is expressed in many adult organs, just as Balzar et al (3) and Schnell et al (2) have summarized in detail. Similar to what they have mentioned in rats, we also observed a gradient of EpCAM from crypts to villi in small intestines of adult mice (Fig. 1; unpublished data). It confirmed that the expression level of EpCAM was high in the proliferative cells and low in the differential cells. Balzar et al reported that in the skin of adult humans, the expression level of EpCAM is low in hair follicles and sweat glands (3). Recently, it has been reported that EpCAM is expressed in the skin Langerhans cells (11). In addition, according to reverse transcription-polymerase chain reaction analysis, EpCAM mRNA is also present in the skin of adult zebrafish (12). Recently, Poon et al (20) studied the expression pattern of EpCAM in rat uterus, and it was revealed that prior to implantation, EpCAM mediates intercellular adhesion in the uterine epithelium, but during implantation, when the uterine luminal epithelial cells lose the majority of their intercellular and cell-matrix adhesions, the expression of EpCAM is decreased, although still present for the maintenance of mucosal integrity.

EpCAM was originally identified as a tumor-associated antigen on the basis of its high expression level in the tumors of epithelial origin (16). EpCAM-positive cells have been suggested to serve as cancer stem cells for various human cancers, including colorectal and hepatocellular carcinoma $(21,22)$. Numerous antibody-based therapeutic approaches targeting EpCAM are currently being developed (23). Further information regarding EpCAM expression in tumors can be found in Balzar et al (3) and Schnell et al (2).

Subcellular distribution of EpCAM. It has been verified that EpCAM is enriched at the basolateral membrane of mouse and human intestinal epithelium. Immunohistochemistry (IHC) staining of the intestinal epithelium of mice with both EpCAM antibody and either E-cadherin antibody or ZO-1 antibody, markers of adherens junctions (AJs) and tight junctions (TJs), respectively, revealed that EpCAM is localized to TJs, AJs and the lateral membranes of epithelial cells lining the mouse intestines (7). In normal human intestinal epithelium, anti-EpCAM antibody stains the region of TJs and the lateral membrane; the EpCAM signal can even be detected on the brush border by immunostaining and immunoelectron microscopy (24). Using domain-specific antibodies, it was demonstrated that EpICD-specific staining is speckled in the cytoplasm, perinucleus and nuclei of FaDu hypopharynx and HCT-8 colon carcinoma cells (25). EpICD may also be detected in the nuclei of carcinoma samples, but does not appear to localize to the nuclei in samples from normal colon biopsies and is detected as distinct speckles in the cell cytoplasm of normal tissues (25).

\section{Functions of EpCAM in physiological processes}

EpCAM and cell junctions. The name EpCAM-epithelial cell adhesion molecule-describes cell-cell adhesion protein. Like most cell adhesion molecules, the primary function of EpCAM appears to be cell-cell interaction (26). This has been supported by the studies with L929 fibroblasts, which are normally not involved in cellular adhesion. The L929 fibroblasts form multicellular aggregates of cells when expressing EpCAM, suggesting that EpCAM is involved in homotypic cell-cell interactions (27). Although a previous study revealed that cells expressing EpCAM were only loosely interconnected (28), further reports have revealed that EpCAM is essential for cell junctions: It interacts with several important cell adhesion molecules (CAMs) and regulates adhesive structures between cells and cell-matrix, including TJs, AJs, desmosomes, and hemi-desmosomes.

EpCAM regulates CAMs. EpCAM and classical cadherins. The E-cadherin gene is extensively studied as a classical cadherin for the whole cadherin superfamily. The early stage results have revealed that E-cadherin exerts opposing effects to EpCAM. E-cadherin acts as a tumor suppressor protein (29-31). Mutational disruption of the E-cadherin gene has been observed in invasive lobular breast cancer and gastric carcinoma (31-33). E-cadherin germline mutations are detectable in families 

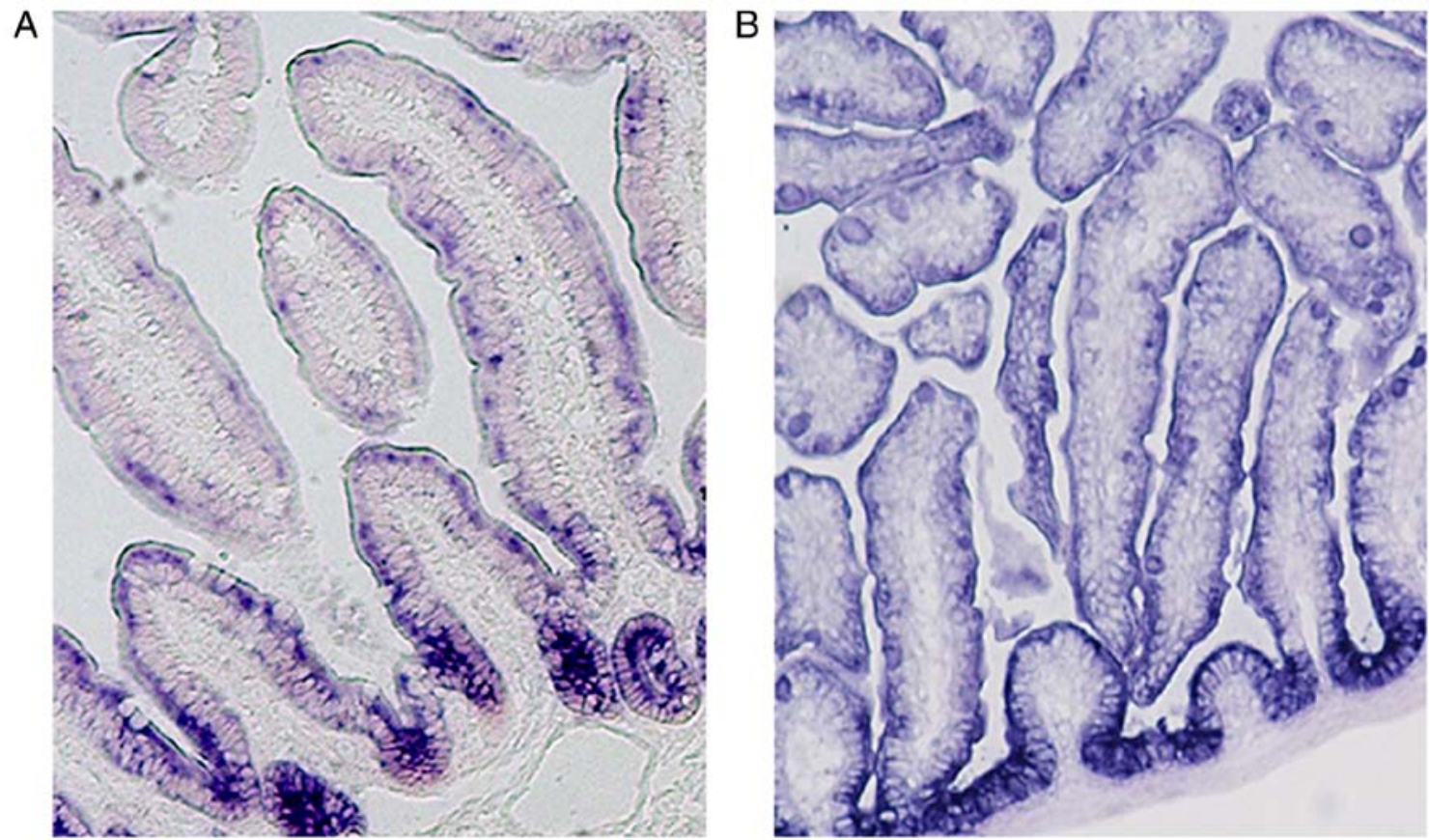

Figure 1. In situ hybridization analysis of EpCAM mRNA in the small intestines of adult mice and E18.5 mouse embryos. (A) The EpCAM mRNA level in crypts was higher compared with in the villi of the small intestine. (B) At E18.5, the expression level of EpCAM in the intervillus domains was higher compared with in villi. EpCAM, epithelial cell adhesion molecule.

with a high frequency of early-onset gastric cancer (32-34). In contrast, EpCAM is highly expressed in a variety of carcinomas and currently considered to be an important carcinoma marker. In cultured murine fibroblast L cells, the expression of EpCAM suppresses the E-cadherin-mediated cell aggregation, because EpCAM disrupts the association of E-cadherin with the cytoskeleton $(35,36)$. It has also been reported that EpCAM affects the cadherin-mediated junctions in HBL-100 cells (35). From these results, it was hypothesized that EpCAM may act as an antagonist of E-cadherin.

However, this conclusion has recently been challenged by EpCAM genetic animal models. In contrast to cell culture studies, Slanchev et al (12) revealed that in the EpCAM mutant enveloping layer (EVL) of zebrafish, the expression level of E-cadherin is reduced; EpCAM and E-cadherin tightly interact for an enhanced effect to promote EVL integrity as well as deep cell epiboly. Each of them is indispensable for EVL integrity, whereas combined loss of both EpCAM and E-cadherin leads to severe layer-autonomous EVL disassembly during early gastrulation stages (12). Several reports have revealed that EpCAM contributes to the formation of functional TJs in the mouse and human intestinal epithelium $(7,9,37)$. Notably, when E-cadherin is deleted from the mouse intestine, the barrier function of the intestines is compromised (38), moreover, loss of E-cadherin in mouse epidermis may lead to improper localization of the key tight junctional proteins, resulting in permeable TJs and altered epidermal resistance (39). From these reports, it was concluded that EpCAM and E-cadherin enhance each other's physiological functions in vivo.

The conclusions from the reduced expression of EpCAM in vivo and in vitro are completely different. The expression of E-cadherin in the CTE children's biopsy specimens is normal (40). The expression level and expression pattern of E-cadherin and $\beta$-catenin are normal in the EpCAM mutant intestines of mouse embryos (7), but their expression levels are disrupted and the intracellular accumulation rapidly increases after birth (8). As these alterations occur following birth, they may be secondary effects of EpCAM mutation. In contrast, in vitro studies suggest that the reduction of EpCAM expression does not change the expression or localization of E-cadherin and $\beta$-catenin in T84 cells (41).

Various EpCAM knockout mice exhibit abnormal placental development and die in utero by E12.5, and the expression of E-cadherin and P-cadherin in E9.5 placentas of these mutant mice are not affected (10). EpCAM is co-expressed with E-cadherin, but the expression of EpCAM is inversely correlated with P-cadherin in mouse placentas, developing guts, lungs and hair follicles (10). However, Wu et al (41) reported that EpCAM and E-cadherin did not precisely co-localize in T84 cell monolayers detected by confocal microscopy, and co-immunoprecipitation studies did not indicate that EpCAM and E-cadherin were tightly associated in T84 cells.

There are two noteworthy exceptions. Global depletion of EpCAM by injection of antisense Morpholino oligonucleotides (EpCAM MO) in Xenopus embryos results in a marked decrease in C-cadherin protein levels, but does not affect mRNA levels (the same was observed for the associated tested molecules E-cadherin, $\alpha$ - and $\beta$-catenin), indicating that the regulation occurs at a posttranscriptional level (14). Cadherin downregulation results from protein kinase $\mathrm{C}$ (PKC) overactivation in EpCAM mutant Xenopus embryos. In EpCAM-depleted Caco-2 cells, a human colon cancer cell line, PKC activation increases and the E-cadherin protein is decreased (14) or mislocalized (42).

EpCAM and claudins. Claudin-7 is the first member of the family of claudins which was reported in a study investigating the association between EpCAM and claudins in both 
non-transformed tissues and metastasizing tumor cell lines (24). Claudin-7 was first detected in a CD44v6-tetraspanis-EpCAM complex, and later it was confirmed that claudin-7 associates directly with EpCAM $(24,43)$. Claudin-7 has been observed in TJs and basolateral membranes; the co-localization of EpCAM and claudin-7 has also been observed on both TJs and basolateral membranes $(7,24)$. Mutant experiments identified that the AxxxG motif in the transmembrane domain of EpCAM is required for association with claudin-7, and claudin-7 is unable to associate with EpCAM if A279 and G282 are changed to I279 and I282 (44).

Claudin-7 is one of the primary claudin proteins expressed in the intestine (45). In EpCAM mutant embryos, claudin-7 protein is downregulated to undetectable levels in all regions of the intestine examined, but claudin-7 mRNA is still normal in the mutant intestine (7). EpCAM and claudin-7 have been demonstrated to colocalize at the basolateral surface of the intestine, pancreas, stomach, lungs and kidneys in wild type (WT) mice, detected by fluorescent immunohistochemistry. Claudin-7 protein is also downregulated to undetectable levels in the pancreas, lungs and stomach of EpCAM knockout mice, but there are still some weak claudin-7 protein signals in the EpCAM mutant kidneys (7). Deletion of the exon 4 in EpCAM leads to decreased expression and mislocalization of EpCAM in the intestinal epithelium rather than along the plasma membrane, meanwhile, the expression of claudin-7 protein is also decreased, and the co-localization with EpCAM $\Delta 4$ protein is lost, although claudin-7 mRNA levels remain unaltered (9). Mueller et al (9) also observed a similar situation of claudin-7 expression in CTE patients. Furthermore, in WT or $\Delta 4$ FLAG-tagged EpCAM transfected HEK293 cells, endogenous claudin-7 combines with WT EpCAM, however not with EpCAM $\Delta 4$. Knockdown of EpCAM in T84 and Caco-2 cells using short hairpin RNA leads to decreased claudin-7 proteins in these cells (41).

As mentioned above, the transmembrane domain of EpCAM is directly associated with claudin-7. Claudin-7 protein is decreased when EpCAM is lost. Claudin-1 and claudin-7 are closely related ( $\sim 50 \%$ homologous at the amino acid level) (46), and their sub-localization is similar. Wu et al (41) revealed that the expression of claudin-1 protein is also decreased following knockdown of EpCAM in T84 and Caco-2 cells, however claudin-1 mRNA remains normal. Notably, the expression of claudin-1 is also reduced in claudin-7 knockout mice (47). It has been confirmed that claudin-7 is associated with claudin-1 and facilitates the incorporation of claudin-1 into EpCAM-containing complexes.

The fact that decreased expression levels of claudin-7 and claudin-1 are associated with the reduction of EpCAM expression indicates that the alterations are post-transcriptional. Inhibition of proteosomes by lactacystin or MG132 are unable to increase the expression of claudin-7 and claudin-1 proteins in EpCAM knockout samples or EpCAM knockdown cells $(7,41)$. Wu et al (41) indicated that claudin-7, claudin-1, and EpCAM turnover occurs via lysosomes, and EpCAM may protect claudin-7 and claudin-1 from lysosomal degradation in Caco- 2 cells, detected by immunofluorescence microscopy and chloroquine treatment experiments (41).

Claudin-7 was not detected in the intestine, lungs, stomach, and pancreas of EpCAM mutant mice, however is still detected in the kidney epithelium, albeit at reduced levels (7). The kidney epithelium may express an EpCAM-like protein that associates with claudin-7. EpCAM-2/Tacstd-2 is a candidate for such an EpCAM-like molecule, given that it is not only structurally related to EpCAM, but also interacts with claudin-1 and claudin-7 in human tissues and cultured cells (48).

In addition to claudin-7, the levels of claudins 2, 3, and 15 are also reduced in the intestine of EpCAM mutant mice (7); claudins 2, 3, 7, and 15 co-precipitate with each other from mouse intestinal lysates. However, claudin molecules associate with each other in a heterotypic as well as homotypic manner in cultured cell lines (49-51). EpCAM may indirectly interact with these claudins and recruit them to the cell-cell junctions, in particular the sub-localization of claudin-2, 3, and 15 is only at the TJs (7). As the distribution and expression levels of claudins 2, 3, 4, and 8 in the kidneys are not affected in claudin-7 knockout mice (52), the precise manner of the interaction between EpCAM and various claudins remains to be determined. AJs have been found to be necessary for the establishment of TJs (53); certain TJ proteins are mislocalized and functional TJs are not formed in the absence of $\alpha$-catenin or cadherin $(39,54,55)$. The structure of AJs appears normal in EpCAM mutant animals, but as mentioned above, their function in maintaining TJs may be affected, which may be the reason for decreased levels of other claudins.

In the mouse intestines, claudin-7, claudin-1 and $\alpha 2$-integrin form a complex (47), therefore it may be hypothesized that this also occurs in other organs. EpCAM directly binds claudin-7, which in turn facilitates the incorporation of claudin-1 into the EpCAM-containing complexes. In many tumor cells, the complex changes to EpCAM-claudin-7-CD4 4v6-tetraspanis (43), which may be important during tumorigenesis.

EpCAM regulates adhesive structures. It has previously been demonstrated that exogenous EpCAM mediates $\mathrm{Ca}^{2+}$-independent homophilic cell-cell adhesion in cultured EpCAM-negative cells. Here, the authors discuss its in vivo cell-cell adhesion functions from the reports of genetic animal models and CTE patients.

Apical junctional complex (AJC). In vertebrate epithelial cells, the apical TJ and the more basally localized AJ form the AJC (56-58). EpCAM mutant zebrafish display a persistent basal extension of AJCs in EVL cells under ultrathin electronic microscopy (12). Ultrathin electronic microscopy results also indicate that TJs of the small intestinal epithelia in EpCAM knockout mice are extended, but freeze-fracture electronic microscopy results suggest that TJs in the EpCAM mutant mouse intestinal epithelia are scattered and dispersed (7). It may therefore be hypothesized that the AJCs in EpCAM mutant EVL cells of zebrafish are also scattered and dispersed. If the TJs scatter, their functions will be affected.

The morphology of AJs in EpCAM mutant intestines is normal, and this may be due to the fact that E-cadherin and $\beta$-catenin are still maintained (7). The mislocalization of TJs indicates that the AJs' function of supporting TJs may be affected; which may be because EpCAM and claudin-7 proteins are lost in AJs. The authors speculate 
that EpCAM and claudin-7, together with E-cadherin, are essential to keep the balance between AJs and cortical tension (Fig. 2A). The loss of EpCAM and claudin-7 would result in loss of balance between AJs and cortical tension, affecting the function of AJs leading to the mislocalization of TJs (Fig. 2B). As mentioned above, in the EpCAM mutant enveloping layer (EVL) of zebrafish, the expression level of E-cadherin is decreased, and the EpCAM mutant zebrafish display a persistent basal extension of AJCs in EVL cells. In summary, these reports suggest that EpCAM regulates the formation, maintenance and functions of AJCs.

Desmosomes. Electron microscopic examination has revealed that the length and number of desmosomes between the enterocytes of CTE patients is increased, and some of them exhibit a distorted structure $(9,40)$. Mueller et al (9) also suggested that the intestines of EpCAM ${ }^{\Delta 4 / \Delta 4}$ mice have sporadic irregularity, with crowding and lengthening desmosomes, as determined using an electron microscope (EM) (9). Using an immunohistochemical assay, Patey et al (40) found that the expression of desmoglein is restricted to the upper part of the intercellular membrane of the epithelial cells lining villi and crypts in the normal small bowel, whereas the expression of desmoglein is expanded with staining all over the lateral membrane of the epithelial cells lining villi and crypts in the intestines of CTE patients. However, the expression levels of the other components of desmosomes, plakoglobin and desmoplakin, were normal. EpCAM knockdown does not lead to marked alteration of the expression and distribution of desmoglein 2 in T84 cells (41). The association between EpCAM and desmosomes in the enterocytes remains unclear. The authors speculate that if the balance between AJs and cortical tension is broken, the components of desmosomes would move to the basal parts of the lateral membrane.

Cell-matrix adhesion. The abnormalities in the composition of the basement membrane of the intestines from CTE patients have been identified, including the enhanced deposition of heparan sulfate proteoglycan (HSPG) and type IV collagen, and extremely faint laminin in the crypt region $(59,60)$. Distribution of $\alpha 2 \beta 1$ integrin adhesion molecules along the crypt-villous axis of CTE patients is abnormal; in the normal small bowel, the $\alpha 2$ subunit is expressed on the epithelial cells lining crypts and is absent on the epithelial cells lining villi, whereas in epithelial dysplasia, the $\alpha 2$-integrin is expressed on the basolateral membranes of the epithelial cells lining both the villi and the crypts $(40,59,60)$.

The cell-matrix adhesion situation in EpCAM mutant animal models remains to be elucidated. As claudin-7 protein levels are decreased to undetectable levels in EpCAM mutant mice, it has been hypothesized that claudin-7 knockout mice may be useful for future investigations. Deletion of claudin-7 alters the normal distribution pattern of $\alpha 2$-integrin; $\alpha 2$-integrin in WT intestines is clearly visualized at the basal membrane, whereas in Claudin $7^{-/-}$intestines, $\alpha 2$-integrin either forms clusters or moves toward the apical lateral. Deletion of claudin-7 also significantly increases the expression levels of matric metallopeptidase (MMP)-3 and MMP-7, which may result in the degradation of extracellular matrix components (47).
The primary reason for abnormalities of cell-matrix adhesion in CTE patients or claudin-7 mutant mice remains to be determined. Basement membrane molecules are involved in the epithelial mesenchymal cell interactions, which are instrumental in the development and differentiation of the intestine (61-66). The changes in the cell-matrix adhesion in EpCAM mutant humans and animals contribute to the behavioral and morphological alterations of the intestine.

Cell transport. The intestinal TJs of EpCAM mutant mice are affected. TJs form a barrier that separates the apical from the basolateral membrane of the epithelium, allowing the selective passage of ions and solutes $(7,58)$. Therefore, EpCAM is a very important molecule that regulates movement of materials across the intestinal epithelium and other epithelial tissues.

Injection of sulfo-NHS-biotin, a probe that physically labels cell membrane proteins, into the intestinal lumen of E18.5 WT and EpCAM mutant embryos revealed that this probe penetrates the mutant intestinal epithelium easily, and the flux of lucifer yellow probe from apical to basal as well as from the basal to apical is increased in the intestine of EpCAM mutant mice at P3.5 (7). EpCAM ${ }^{\Delta 4 / \Delta 4}$ mice show intestinal permeability defects, with the FITC-dextran crossing the mutant intestinal barrier into the bloodstream more quickly compared with WT mice (9). Together, these reports suggest that the barrier function of the intestine is impaired in EpCAM mutant mice.

As mentioned above, the results of electron microscopy showed that TJs mis-localize in EpCAM mutant intestines, and the combined downregulation of claudins-2, 3, 7, and 15 may be observed in the intestinal epithelium of EpCAM mutant mice (7). Claudin-2 and claudin-15 are responsible for paracellular permeability of $\mathrm{Na}^{+}(67)$. Lei et al (7) found that in EpCAM mutant mice, $\mathrm{NaCl}$-dilution potential is lowered, and $\mathrm{Na}^{+}$-selective paracellular permeability is reduced while $\mathrm{Cl}^{-}$-selective permeability remains normal (7), like in the claudin-15 mutant mice (67). Combined downregulation of claudins may result in diarrhea in EpCAM mutant mice and CTE patients. Knockdown of EpCAM may also lead to significant reduction of Trans-epithelial Electrical Resistance in T84 and Caco-2 cell lines (41).

Cell exosomes. Extracellular vesicles (EVs) detach from the cell membrane or bilayer membrane secreted by cells, and are mainly composed of apoptotic bodies, ectosomes, extranuclear particles, cell microbubbles and exosomes (68). Exosomes are released to the outside of the cell by extracellular secretions from the intracellular multivesicular bodies after fusion with the cell membrane, with a diameter of $\sim 40$ to $100 \mathrm{~nm}$. EVs carry a variety of proteins, lipids, DNA, mRNA and miRNA, which are involved in intercellular communication, cell migration, angiogenesis and immune regulation $(69,70)$. Increased levels of EVs may act as diagnostic markers of diabetes, cardiovascular disease, AIDS, chronic inflammatory diseases and cancers, therefore the accurate characterization and research of EVs is particularly important (71).

It has been demonstrated that EpCAM is essential for the gastrointestinal localization of some EVs secreted from the intestinal epithelia cells (IECs) (72). Under physiological conditions, IECs produce EVs with transforming growth 

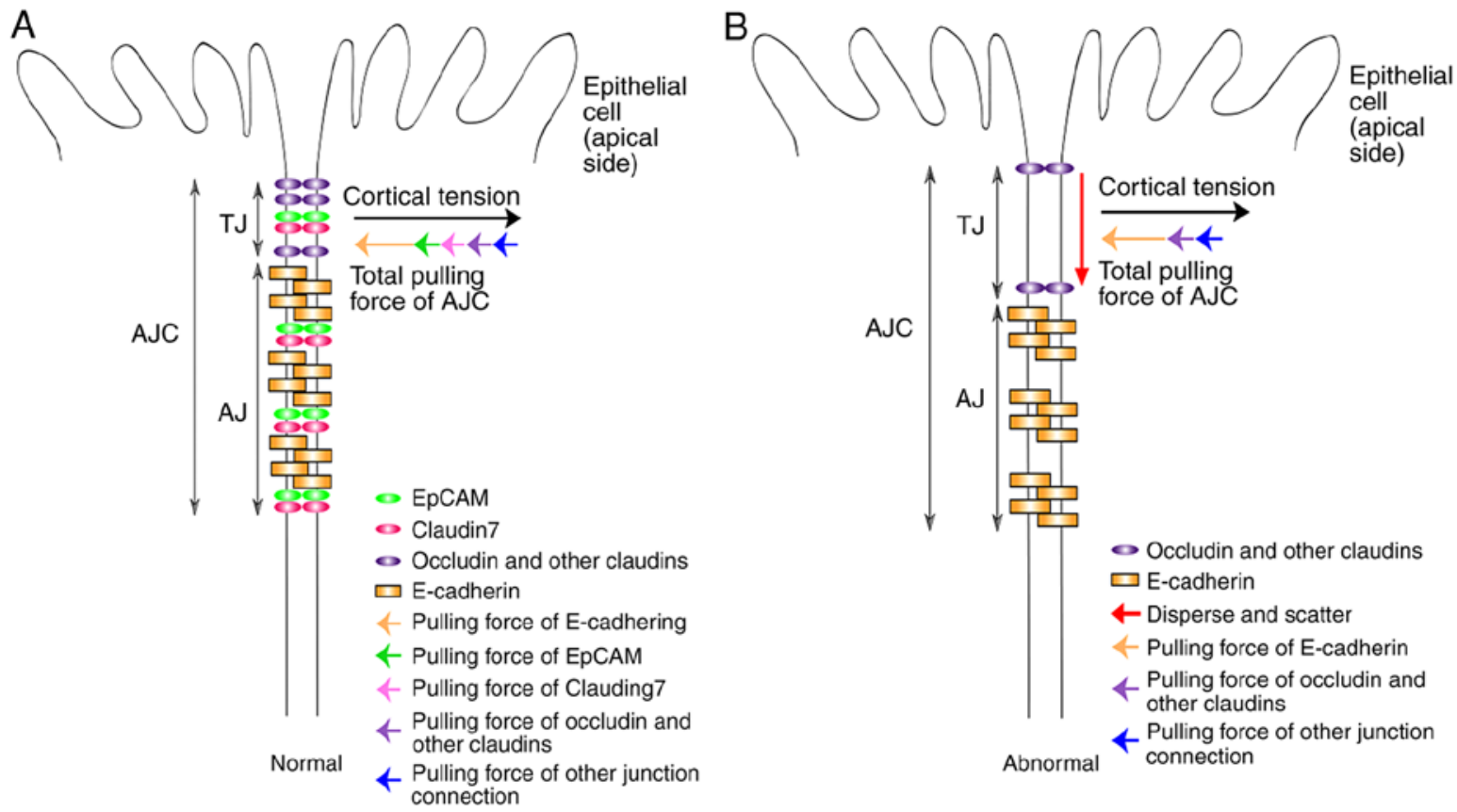

Figure 2. Schematic representation of the function of EpCAM in cell-cell adhesive structures. (A) In the normal intestinal epithelium, EpCAM and claudin-7 complex, together with E-cadherin, is essential to keep the balance between AJs and cortical tension. The strength of the total pulling force from E-Cadherin, EpCAM, claudin-7, other claudins, occludin and other junction connections is equal with the cortical tension between two epithelial cells; but the direction of the total pulling force is opposite to that of cortical tension. With this balance, AJs support TJs to keep the normal structure and functions of TJs. (B) In EpCAM knockout intestinal epithelium, the EpCAM and claudin-7 complex is completely lost; as is the balance between AJs and cortical tension. Therefore, the support of AJs to TJs becomes weak. TJs will therefore disperse and scatter with the EpCAM mutation and functions of TJs are also affected. EpCAM, epithelial cell adhesion molecule; AJs, adherens junctions; TJs, tight junctions.

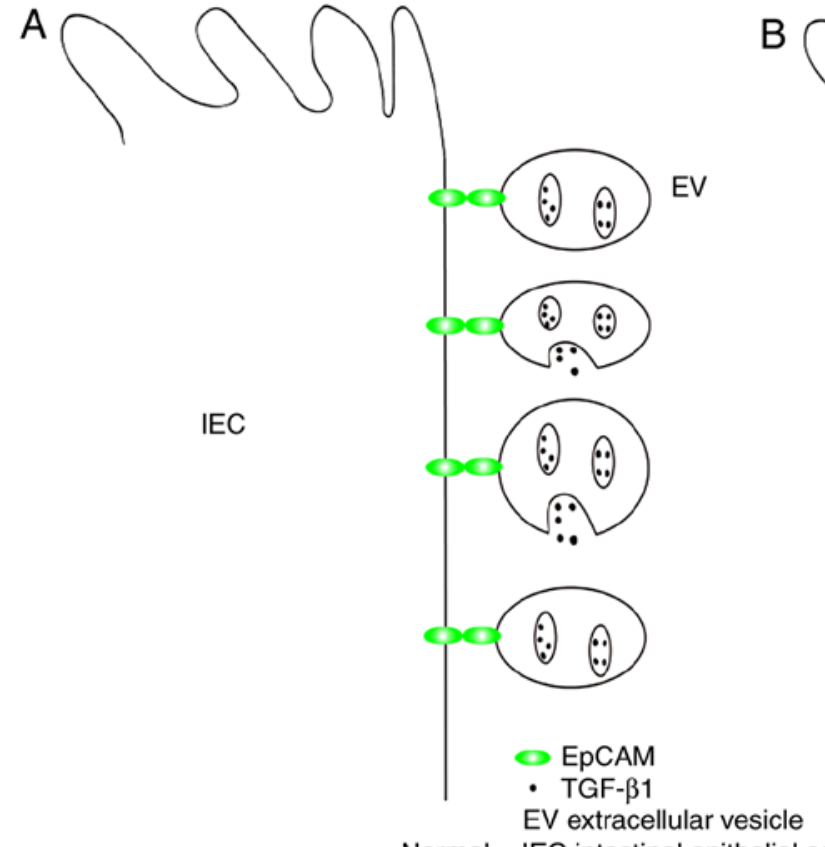

Normal IEC intestinal epithelial cel

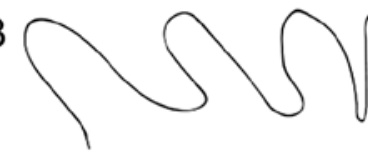

IEC

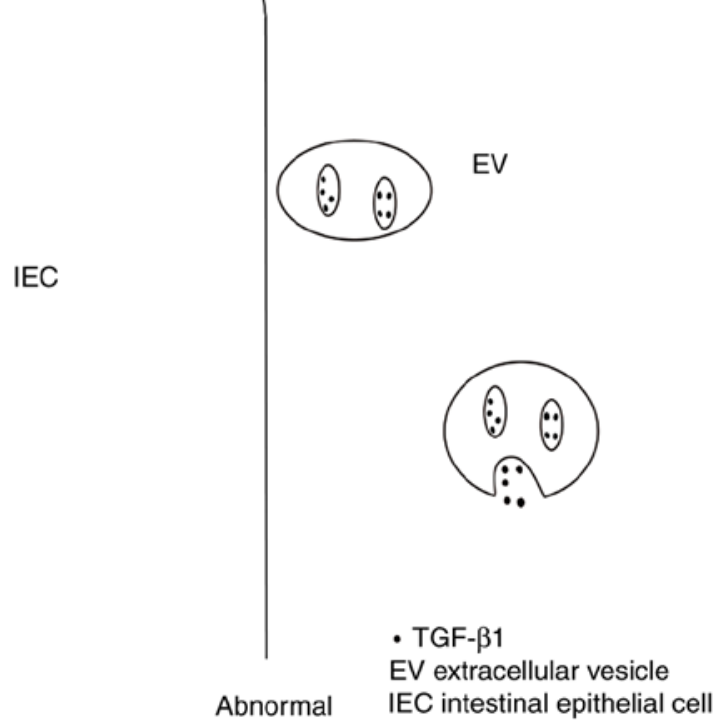

Figure 3. Schematic representation of the function of EpCAM in the recruitment of EVs in the intestine. (A) EVs with TGF- $\beta 1$ produced by the IECs bind to IECs through EpCAM molecules which are localized in the membranes of EVs and IECs respectively. Therefore, these EVs can be recruited to the intestine. (B) EVs are unable to localize in the intestine when EpCAM gene is deleted in the IECs. EVs, extracellular vesicles; TGF- $\beta 1$, transforming growth factor- $\beta 1$; IECs, intestinal epithelial cells; EpCAM, epithelial cell adhesion molecule.

factor (TGF)-ק1-dependent immunosuppressive activity (72). By inducing regulatory $\mathrm{T}$ cells and immunosuppressive dendritic cells, the transfer of EVs into inflammatory bowel disease (IBD) mice induced by dextran sulfate sodium could improve the symptoms of IBD. Conversely, reduced production of endogenous EVs may promote the development of 


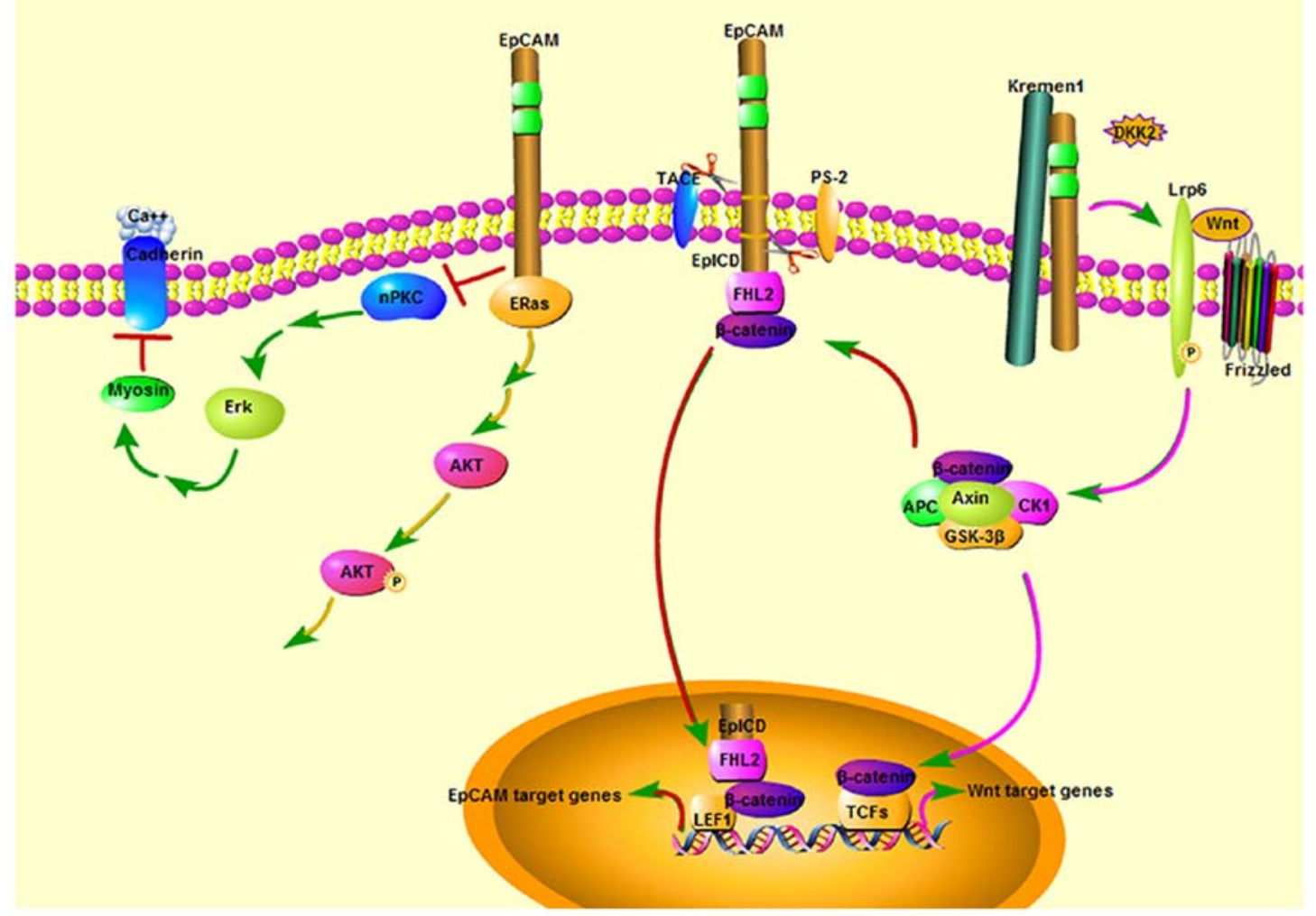

Figure 4. Overview of the role of EpCAM in cell signaling. From the available data, EpCAM has emerged as a crucial signaling molecule, controlling four independent pathways. i) The nPKC-dependent pathway: The EpCAM cytoplasmic tail inhibits the nPKC activity and ERK pathway to protect cadherin-mediated adhesion. ii) Wnt signal pathway: EpCAM extracellular domain directly binds to Kremen1 and disrupts the Kremen1-Dkk2 interaction, which prevents Kremen1-Dkk2-mediated removal of Lrp6 from the cell surface. EpCAM derepresses Lrp6 and cooperates with Wnt ligand to activate the Wnt signaling through stabilizing membrane Lrp6 and allowing Lrp6 to cluster into active signalosomes. iii) ERas/AKT pathway: EpCAM fosters the activating phosphorylation of AKT at serine473 by interacting with hyperactive Ras GTPase ERas, which induces the activation of AKT. iv) In tumor cells or ES cells, EpICD forms a transcription activator complex with FHL2, $\beta$-Catenin and LEF-1 to increase transcription of EpCAM target genes, such as c-Myc and Cyclins A/E. Dkk2, Dickkopf2; Lrp6, Lipoprotein-receptor-related protein 6; EpCAM, epithelial cell adhesion molecule; PKC, protein kinase C; ERK, extracellular signal regulated kinase; ERas, embryonic Ras; AKT, RAC- $\alpha$ serine/threonine-protein kinase; EpICD, intracellular domain of EpCAM; FHL, four and a half LIM domains; LEF-1, lymphoid enhancer binding factor 1.

IBD (73). During the development of IBD, IECs produce EVs with elevated TGF- $\beta 1$ levels in an extracellular signal regulated kinase-dependent manner. These EVs tend to localize in the gut through associating with EpCAMs of IECs (Fig. 3). Knockdown of EpCAM in vivo increases the severity of IBD in mice, and as the expression level of EpCAM decreases, the protective effect of EVs on murine IBD is attenuated (74). Therefore, the function of EpCAM in the localization of EVs is very important for numerous physiological or pathological processes.

Cell polarity. The AJCs play crucial roles in the formation of the polarity and the maintenance of tissue architecture (58). Since EpCAM contributes to the formation of functional AJCs, it may be important for the polarity of epithelial cells.

Salomon et al (42) reported that brush border components of the enterocytes, such as villin and ezrin, partially disappear, but relocate at the lateral membranes in CTE patients. They further revealed that apical polarity proteins, such as crumbs 3 , cell polarity complex component, protein kinase $\mathrm{C}$ and par-3 family cell polarity regulator, relocate laterally at the tricellular contacts of EpCAM silenced Caco- 2 cells, but the basal polarity is normal. Wu et al (41) found that EpCAM knockdown does not change the expression or distribution of CD26 (on apical membrane surfaces), Na/K-ATPase (on basolateral surfaces), or the subapical localization of myosin IIA, and they concluded that effects of EpCAM on TJs are selective, and do not cause gross abnormalities in the cell polarity. $\mathrm{Na} / \mathrm{K}$-ATPase proteins are also normal in the enterocytes of CTE patients (42). It has been suggested that more cellular polarity markers should be investigated in EpCAM mutant animal models.

Signaling. From the available data, EpCAM emerged as a crucial signaling molecule, controlling four independent pathways (Fig. 4). One pathway regulates cell proliferation via nuclear activities in tumor cells, which is involved in $\beta$-catenin-dependent transcription (25). Here, the authors discuss three signaling pathways in the developmental processes.

The nPKC-dependent pathway. Loss- and gain-of function of EpCAM in Xenopus embryos revealed that EpCAM acts as a potent inhibitor of novel protein kinase $\mathrm{C}$ (nPKC) during development $(13,14)$. PKC inhibition is caused by a short segment of the EpCAM cytoplasmic tail. This motif 
resembles the pseudosubstrate inhibitory domains of PKCs and bound nPKCs with high affinity. The effects of loss of EpCAM on the amphibian embryo tissues have been observed, including sequentially strong overstimulation of PKC activity and the Erk pathway, exacerbated myosin contractility, loss of cadherin-mediated adhesion, tissue dissociation, and, ultimately, cell death (14). Elevated EpCAM levels in either the ectoderm or the mesoderm result in tissue mixing, and this property relies on a novel signal function through downregulation of nPKC activity (13). This activity of EpCAM does not require its extracellular domain, but its cytoplasmic motif is essential. A bioinformatics search revealed the existence of similar motifs in other plasma membrane proteins, most of which were cell-cell adhesion molecules. Thus, direct inhibition of PKC by EpCAM represents a general mode of regulation of signal transduction by cell-surface proteins (14).

Wnt signal pathway. EpCAM has been identified as an endoderm-specific Wnt activator in zebrafish; EpCAM mutants exhibit defective liver development similar to prt/wnt2bb mutants (15). It has been revealed that EpCAM that is directly bound to Kremen1 disrupts the Kremen1-Dickkopf2 (Dkk2) interaction, which prevents Kremen1-Dkk2-mediated removal of lipoprotein-receptor-related protein 6 (Lrp6) from the cell surface. EpCAM activates Lrp6 and cooperates with Wnt2bb ligand to activate the Wnt signaling through stabilizing membrane Lrp6 and allowing Lrp6 to cluster into active signalosomes. Thus, EpCAM autonomously promotes and cooperatively activates Wnt $2 \mathrm{bb}$ signaling in the endodermal cells of zebrafish embryos (15).

It has also been revealed that in EpCAM mutant embryos, injection of EpCAM or EpCAM extracellular domain (ECD) mRNA rescues the diminished expressions levels of fgf 3 and $\mathrm{dkk} 1 \mathrm{~b}$, the downstream factors of Wnt signaling in the lateral line primordia. Therefore, it has been speculated that similar mechanisms may also be present in the development of other cellular systems such as lateral line primordia in which Wnt and EpCAM are active $(75,76)$.

Embryonic Ras (Eras)/RAC- $\alpha$ serine/threonine-protein kinase (AKT) pathway. It has previously been reported that EpCAM regulates murine ES cell differentiation via ERas/AKT pathway. ERas has been identified as a novel EpCAM interactor through co-immunoprecipitation, and these two proteins have a similar expression pattern in murine ES cells and embryos. The expression of EpCAM fosters the activating phosphorylation of AKT at serine 473 by interacting with hyperactive Ras GTPase ERas, which induces the activation of AKT. It has been demonstrated that full-length EpCAM is essential for this signaling pathway, but the detailed mechanism is still unclear. EpCAM may orchestrate the differentiation of ES cells through this signaling pathway (77).

Proliferation. Reports regarding the function of EpCAM on the regulation of proliferation are contradictory. It has been reported that enhanced expression of EpCAM is associated with active proliferation of cancerous or normal tissues (78). EpCAM has also been found to increase the proliferation of tumor cell lines $(79,80)$. Maetzel et al $(25)$ revealed that knockdown of EpCAM in FaDu cells results in decreased proliferation, and they concluded that the proliferative action of EpCAM was attributed to the ability of EpICD to form a transcription activator complex with four and a half LIM domains $2, \beta$-Catenin and lymphoid enhancer binding factor 1 (LEF1) (Fig. 4). However, this mechanism could not be verified by EpCAM mutant animal models. Lei et al (7) found that the number of Ki67-positive cells in the intervillus domains of EpCAM mutant mice at E18.5 was similar to that in WT animals throughout the intestine. Mueller et al (9) assessed enterocyte proliferation using BrdU at a $4 \mathrm{~h}$ time point following intra-peritoneal injection, and found that $\mathrm{EpCAM}^{\Delta 4 / \Delta 4}$ mice demonstrate a significantly higher proliferation index compared with WT mice. Furthermore, knockdown of EpCAM in T84 and Caco-2 cells increases cell proliferation (41). Overexpression of EpCAM in invasive colon cancer cell lines may reduce cell proliferation. These reports indicate that EpCAM may inhibit the proliferation of progenitor cells of the intestinal epithelium, but the molecular mechanism remains to be fully elucidated.

Motility. EpCAM is a cell adhesion molecule, however it has been revealed that it may function to enhance the mobility of cells and tissues. In 2004, Osta et al (80) reported that EpCAM has a stimulatory effect on in vitro cell migration. Moreover, it was found that in both Zebrafish and Xenopus embryos, EpCAM is required to enable cells to rearrange during epiboly, a morphogenetic process through which the ectoderm thins and expands during gastrulation $(12,13)$. Furthermore, in conditional knockout mice, loss of EpCAM impairs the migration of skin Langerhans cells (11). The fact that the migration of cells and tissues may be promoted by a cell adhesion molecule is quite counterintuitive. EpCAM may act to increase the expression of cadherins (12-14), which further adds to the puzzle. Maghzal et al (13) reported that EpCAM positively regulates both cell movements and cadherin levels in Xenopus embryos, but they demonstrated that the regulation of cell motility occurs independently of the stabilization of cadherins. Motility and normal epiboly may be rescued in EpCAM-depleted tissues of Xenopus embryos by expression of an EpCAM construct lacking the whole extracellular domain (13). EpICD may control the activity of nPKCs, and thus moderate actomyosin-based contractility (14).

However, a contrasting result was observed in the intestinal epithelium of mice. To assess the migration of enterocytes in EpCAM mutant mice, BrdU positive cells were assessed at $24 \mathrm{~h}$, and the result revealed that $\mathrm{EpCAM}^{\Delta / \Delta 4}$ mice have significantly higher migration rates of BrdU positive enterocytes compared with WT mice (9).

\section{Functions of EрCAM in development and stem cells}

EpCAM is highly expressed in many embryonic tissues of vertebrates and in numerous types of progenitor cells and stem cells. Research has been focused on its functions in developmental processes and stem cells.

Development. Previously it has been demonstrated that EpCAM is required to form cells of all germ layers using EpCAM mutant murine ES cells (77); but EpCAM knockouts 
in mice and EpCAM null mutants in Zebrafish give relatively weak embryonic phenotypes $(7-9,12,75)$. It was speculated that the EpCAM-2 gene which presents in both species functions redundantly $(7,14)$. It has been confirmed that EpCAM is essential for intestinal epithelium homeostasis in mice and humans (7-9), and is also required for the integrity of skin in adult zebrafish (12).

One EpCAM mutant could cause mouse embryonic lethality through placental defects, and it was demonstrated that EpCAM is required for the differentiation or survival of parietal trophoblast giant cells, normal development of the placental labyrinth and establishment of a competent maternal-fetal circulation (10). Lei et al (7) also demonstrated that the frequency of homozygous mutant mice is slightly smaller than expected $\left(22.43 \%\right.$ for $\mathrm{EpCAM}^{-/}$and $13.76 \%$ for

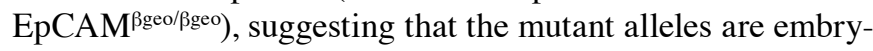
onic lethal in a small proportion of mutant homozygotes. Maghzal et al (14) reported that global depletion of EpCAM results in Xenopus embryonic lethality with strong penetrance $(>90 \%)$, and EpCAM is crucially required for tissue integrity. EpCAM therefore has important functions at different developmental stages of vertebrate embryos.

EpCAM is highly expressed in human hepatic stem cells and progenitor cells, however is absent in mature hepatocytes $(78,81,82)$. Knockout of EpCAM in zebrafish induces defective early hepatic development; but hepatocytes keep proliferating in EpCAM mutants, and the liver becomes relatively normal at 8 days postfertilization (15). Overexpression of EpCAM in murine ES cells may increase the transcription of hepatocytic markers Afp and Fn1 (77). Therefore, it is suggested that liver development in EpCAM knockout mice at early stages should be investigated.

Stem cells. In 1993, it was demonstrated that EpCAM is highly expressed in undifferentiated mouse P19 embryonal carcinoma cells, however is downregulated in differentiated P19 cells (83). It has been confirmed that EpCAM is implicated in the maintenance of pluripotency in embryonic stem cells (ESCs) $(77,84,85)$ as well as in somatic stem cells such as hepatic stem cells $(4,81,86,87)$. The functions of EpCAM in stem cells have been explored for many years. Regulated intramembrane proteolysis (RIP) and nuclear translocation of the EpICD of EpCAM was reported in murine and human ESCs $(85,88)$. It has been demonstrated that in human and porcine ESCs, EpICD supports pluripotency through activation of the transcription of reprogramming factors, such as SRY-Box 2, Oct3/4 and Nanog $(85,89,90)$. The molecular functions of EpCAM in somatic stem cells remain unknown.

It was revealed that the EpCAM and claudin-7 complex has important functions in human and murine somatic cell reprogramming processes (89). EpEX/EpCAM, combined with Oct $3 / 4$ or Kruppel like factor 4 , is sufficient to generate human induced pluripotent stem cells (iPSCs) (91). The EpCAM complex may activate the transcription of Oct4 and suppress the p53-p21 pathway to enhance the pluripotency reprogramming (89). EpEX/EpCAM may additionally activate signal transducer and activator of transcription 3 (STAT3), and the activated STAT3 may lead to the nuclear-translocation of hypoxia inducible factor 1a to promote somatic cell reprogramming (91).

\section{Functions of EpCAM in diseases}

EpCAM and CTE. CTE was firstly reported in 1994 (55), which is a disease characterized by a classical congenital disorder of the intestinal mucosa, including subtotal villous atrophy with crypt hyperplasia and focal crowding of surface enterocytes, resembling tufts. With an incidence estimated at 1 per 50,000-100,000 in Western Europe, there is a high rate of mortality in young children with CTE (92). Non-syndromic CTE has been associated with the mutations of EPCAM, mainly loss-of-function mutations, in $73 \%$ of patients. In $21 \%$ of patients with CTE, a syndromic form is associated with the missense mutations of serine peptidase inhibitor, kunitz type 2 (SPINT2), an inhibitor of HGF activator serine protease (also known as HAI-2) (92). It has been demonstrated that SPINT2 inhibits the activity of cell surface serine protease matriptase, and mutations of SPINT2 lead to efficient cleavage of EpCAM by matriptase (41). Microvillus atrophy has been demonstrated to be present in the biopsy samples of patients with CTE have mutations in EPCAM or SPINT2, which may explain, at least in part, the intestinal failure (93).

CTE causes lethal diarrhea in newborns, and it may be caused by impaired barrier function of TJs in the intestinal epithelium of patients. It has been confirmed that molecular probes, such as sulfo-NHS-biotin, lucifer yellow and FITC-dextran, cross the EpCAM mutant intestinal epithelium more easily compared with in control animal models. This leads to a continuous water leak in the intestines of CTE patients and EpCAM mutant mice.

Claudin-2, 3, 7 and 15 are reduced in the intestinal epithelium of EpCAM mutant mice (7). Some of these claudins are required for the nutrient absorption of intestines. Both claudin-2 and claudin-15 function in the paracellular permeability to $\mathrm{Na}^{+}$in the small intestinal epithelium (94-98). This permeability permits $\mathrm{Na}^{+}$to access the lumen to support the $\mathrm{Na}^{+}$-dependent absorption of nutrients, including glucose, amino acids, vitamin $C$ and others (99-101). The changes in the expression patterns of claudin- 2 and claudin-15 in the small intestine occur age-dependently. The claudin- 2 level is higher than that of claudin-15 in the infant small intestine, but in adults, the expression level of claudin-15 is higher than that of claudin-2 (67,102). Knockout of claudin-15 could lead to $\mathrm{Na}^{+}$ deficiency and glucose malabsorption in the small intestines of adult mice (67). Knockout of both claudins 2 and 15 would cause defects in paracellular $\mathrm{Na}^{+}$flow and nutrient transport in the small intestines and finally lead to mortality from malnutrition, and the mice only survive 25 days after birth (103). From these reports, it may be suggested that the nutrient absorption in the small intestines of CTE patients may be affected.

The mechanisms for the tuft-like structure formations in CTE are not completely clear. The apical polarity of the enterocytes from CTE is affected, which may result in tuft formation. The proliferation and mobility of EpCAM mutant intestinal epithelial cells is also altered, which may be an additional cause of tuft formation. There is no curative treatment for CTE yet, therefore elucidation of the mechanisms underlying tuft formation is very important for the treatment of CTE.

EpCAM and tumors. Originally identified as a novel tumor-specific cell surface antigen following immunization of 
mice with cancer cells in 1970s (1), EpCAM has been known to be highly expressed in a variety of epithelial carcinomas (104). EpCAM is also highly expressed in acute myeloid leukemia (AML), and EpCAM-positive cells may be leukemia stem cells which could promote leukemic progression (105). It has been reported that EpCAM is involved in tumorigenesis, metastasis, and cancer stem cells $(25,106,107)$.

Previous research has focused on the function of EpCAM in cancers. Maetzel et al (25) firstly demonstrated that a proteolytic fragment of EpCAM containing EpICD forms a complex with $\beta$-catenin and LEF-1, which translocates to the nucleus and activates the transcription of genes associated with cell proliferation, such as c-Myc and cyclins A and E, thereby promoting oncogenesis (25) (Fig. 4). This mechanism depends on the cellular interaction to provide initial signals of regulating intramembrane proteolysis (108). A complex of EpCAM, claudin-7, CO-029, and CD44v6 is frequently formed in colorectal cancer, and this complex, but not the individual molecules, may promote the progression of colorectal cancer and increase the apoptosis resistance of cancer cells (43). EpCAM may promote the chemotherapeutic resistance of myeloid leukemia via the Wnt5b singling pathway (105). Previously, Wang et al (107) demonstrated that EpCAM regulates epithelial-mesenchymal transition (EMT), stemness and metastasis of nasopharyngeal carcinoma cells through the phosphatase and tensin homolog (PTEN)/AKT/ mechanistic target of rapamycin kinase (mTOR) pathway. They revealed that overexpression of EpCAM reduces the expression level of PTEN, and then the phosphorylation levels of AKT, mTOR, p70S6K and 4EBP1 are increased with the reduction of PTEN. It may be hypothesized that EpCAM has similar functions in other types of cancers. The elucidation of these molecular mechanisms is an important guide in the effective development of therapies for tumors.

EpCAM has become a therapeutic target in many types of cancers. The emergence of chemotherapeutic drug resistance in cancer stem cells is a key factor hindering the effective treatment of many cancers. A novel system by conjugating cancer stem cells targeting EpCAM aptamer with a chemotherapeutic drug can eliminate chemotherapeutic drug resistance. Incubation of the chemotherapy drug doxorubicin with colorectal cancer cells could lead to the long-term retention and enrichment of adriamycin in the nucleus, thus weakening the therapeutic effect (109). Doxorubicin targeted EpCAM aptamer therapy in tumor-bearing nude mice may significantly inhibit tumor growth, prolong survival time and lead to a prolonged dose-dependent tumor latency. In general, conjugation of cancer stem cells targeting EpCAM aptamer with a chemotherapeutic drug could transform conventional chemotherapeutic drugs into tumor killers to overcome the drug resistance in tumors (110). Zheng et al (105) also found that the EpCAM antibody sensitizes the chemoresistant myeloid leukemia to innate immune cells. It has been reported that exosomes in the circulatory system derived from tumors, called extracellular vesicles or vesicles, may easily be isolated using anti-EpCAM antibodies in combination with magnetic beads. The exosomes are isolated by various downstream assays such as sandwich immunization assay and RT-qPCR. The isolated exosomes could be used to study the distribution of tumor-specific extracellular body surface proteins and associated miRNAs (111). Dendritic cells play a crucial role in the host immune response and antigen presentation. EpCAM peptide-primed dendritic cell vaccinations exhibit significant anti-tumor immunity in hepatocellular carcinoma cells (107).

However, it has been revealed that EpCAM could be a tumor suppressive protein in certain types of cancers. Hwang et al (112) suggests that decreased expression of EpCAM is an early event in oral carcinogenesis. Gosens et al (113) observed that reduced EpCAM expression at the invasive margin of rectal carcinomas, and reduction of EpCAM expression may increase the risk of local recurrence. A recent report revealed that loss of EpCAM increases the malignancy of endometrial carcinoma (EC), and high EpCAM expression favors the survival of patients with EC (114). The molecular mechanisms of the tumor suppressive function of EpCAM in these cancers are not yet clear.

EpCAM and inflammatory bowel disease. Inflammatory bowel disease (IBD) refers to chronic inflammatory disorders in the gastrointestinal tract (115). Crohn's disease and ulcerative colitis are two clinical forms of IBD (116), and the precise aetiology is unclear. It has been reported that intestinal barrier function of patients with IBD is compromised $(117,118)$. The reduction of expression of several cell adhesion molecules has been found in IBD patients (119-123). As mentioned above, knockdown of EpCAM in large intestines of mice increase the severity of murine IBD induced by dextran sulfate sodium salt (124). However, EpCAM is present at normal levels and location in the tissue specimens from patients with Crohn's disease and ulcerative colitis (9). There is no clear evidence that EpCAM mutation could cause IBD.

The claudin-7 protein is reduced to undetectable levels in the intestines of EpCAM mutant mice and CTE patients. The inflammatory and immune responses are clearly observed in Claudin $7^{-/-}$intestines, including an increased number of leukocytes and macrophages, increased mRNA level of interleukin (IL)-1 $\beta$, IL- 8 receptor $\beta$, IL-6, AP- 1 and tumor necrosis factor (TNF)- $\alpha$, increased protein expression levels of nuclear factor $\kappa \mathrm{B}(\mathrm{NF}-\kappa \mathrm{B})$, c-Jun, c-Fos, and cyclooxygenase 2 (COX-2), and elevated phosphorylations of NF- $\kappa$ B and $c-j u n(47,125)$. Claudin-7 mutant mouse models therefore exhibit IBD-like symptoms.

In fact, an inflammatory infiltration may be detected at day 4 in the intestines of $\operatorname{EpCAM}^{\Delta 4 / \Delta 4}$ mice (9). However, absent or mild inflammation may be observed in the intestinal biopsies from CTE patients $(126,127)$. In JAM-A-deficient mice, TGF- $\beta$-producing $\mathrm{CD}^{+}{ }^{+} \mathrm{T}$ cells promote $\mathrm{IgA}$ secretion to protect intestinal inflammation (128), confirming that impaired intestinal barriers induce adaptive immune compensation. The intestinal barrier function is affected in EpCAM mutant mice, but it is normal in claudin-7 knockout mice $(47,125)$. The impaired intestinal barrier of EpCAM mutant mice or CTE patients may induce adaptive immune compensation to protect the intestine from inflammation. EpCAM may also protect intestines from inflammation via binding EVs with TGF- $\beta 1$ (124).

CTE patients may be more sensitive to IBD induced factors, and the EpCAM expression reduction would increase the severity of human IBD. 
EpCAM and cholestatic liver diseases. Cholestatic liver injury is a very big clinical problem, but underlying specific pathological processes are unknown. Recently, Song et al (129) reported that overexpression of long non-coding RNA H19 promotes cholestatic liver fibrosis through zinc finger E-box binding homeobox 1 (ZEB1)/EpCAM pathway. H19RNA interacts with the transcriptional suppressor ZEB1 and inhibits its binding to the EpCAM promoter, thus promoting the expression of EpCAM. The increased EpCAM may result in development of cholestatic liver fibrosis. It was additionally revealed that $\mathrm{H} 19$ and EpCAM are both highly expressed in liver specimens from primary sclerosing cholangitis and primary biliary cholangitis patients. As EpCAM is a downstream gene of H19, the overexpression of EpCAM may promote cholestatic liver injury. The exact molecular mechanisms of EpCAM in promoting cholestatic liver injury are still unclear, but EpCAM is a marker of biliary hyperplasia (130) and may drive cholangiocyte proliferation to promote the development of cholestatic liver fibrosis.

\section{Conclusions and perspectives}

EpCAM has been recognized to exhibit broad spectrum functions in multiple physiological and pathological processes. It is essential for the homeostasis of epithelial tissues through regulating cell-cell junctions, signaling pathways, cellular proliferation and mobility. It is a very important molecule that maintains the pluripotency of ES cells and promotes the iPSCs process. Mutations or aberrant expression levels of EpCAM are associated with numerous diseases including many types of cancers.

EpCAM is a cell adhesion molecule that plays important roles in the formation and functions of adhesive structures and polarity. However, EpCAM is highly expressed in tumor tissues, and the tumor tissues usually lose organized adhesive structures and cell polarity. These two things seem contradictory. The clear understanding of different functions of EpCAM in normal and cancer tissues will play an important role in exploring the potential therapeutic strategies for cancers. Tissue-specific mutant and overexpression animal models would be very useful to explore these molecular mechanisms.

From mutant animal models, it was concluded that EpCAM has important roles in both the intestinal epithelium and the placental labyrinth. These two tissues both function on the absorption of nutrients. Knockout EpCAM in mice impairs the intestinal barrier function and causes ion transport dysfunction in the intestinal epithelium $(7,9,37)$. The nutrient absorption ability of the placental labyrinth may also be affected, which may be a cause of embryonic lethality. The EpCAM expression level is higher in the crypts of the small intestine than in the villi $(2,3)$, and it has been demonstrated that the EpCAM expression level is also higher in the multipotent labyrinth trophoblast progenitor cells than other parts of the placental labyrinth in mice (131). EpCAM may have similar functions in regulating the development of these two tissues.

The different mechanisms underlying the roles of EpCAM in cancer tissues and the trophectoderm have yet to be elucidated. EpCAM is highly expressed in both types of tissue. Trophoblasts can invade and branch out within uterine epithelium (132), but the invasive ability of trophoblasts is very limited. EpCAM is associated with the metastasis of cancer cells (106), and the invasive ability of cancer cells is uncontrollable. Elucidation of these different mechanisms would be helpful in exploring the therapeutic ways to control the metastasis of cancers.

EpCAM is expressed in many types of epithelia in adult animals and humans, and may have important functions in these tissues. Therefore, conditional knockout animal models are required to study these functions. EpCAM is under the control of transcriptional factor grainyhead like transcription factor 2 (Grhl2), and in the otic epithelium of Grhl2 mutant zebrafish, EpCAM protein is markedly reduced (133). Grhl2 mutation is associated with hearing loss in humans, and the hearing and balance system is severely disrupted in EpCAM mutant zebrafish (133). EpCAM may have functions in otic epithelium of humans and animals. It has been reported that CTE patients also suffer from various other condition, including chronic arthritis $(2,134,135)$. These reports confirmed that EpCAM has various functions in multiple organs of adults. The molecular mechanisms of these functions remain unclear. Elucidation of the molecular functions of EpCAM will be useful for its role as a therapeutic target in the future.

\section{Acknowledgements}

The authors would like to thank Professor Xianglu Rong, Professor Weijian Bei, and Professor Dewei Ye from Guangdong Metabolic Disease Research Center of Integrated Chinese and Western Medicine, Guangdong Pharmaceutical University for their fruitful discussions.

\section{Funding}

This work was supported by grants from the National Natural Science Foundation of China (grant no. 31671520), the International Cooperation Project of the Science and Technology Department of Guangdong province (grant no. 2015A050502050) and the Construction Project of International Cooperation Base of the Science and Technology Department of Guangdong province (grant no. 2016B050501003).

\section{Availability of data and materials}

Not applicable.

\section{Authors' contributions}

ZL and JG conceived the review and analyzed the relevant literature. LH collected literature and wrote the first draft of the manuscript. YY collected literature and critically revised the manuscript. FY and SL collected literature. ZZ created the figures.

\section{Ethics approval and consent to participate}

Not applicable. 


\section{Patient consent for publication}

Not applicable.

\section{Competing interests}

The authors declare that they have no competing interests.

\section{References}

1. Herlyn M, Steplewski Z, Herlyn D and Koprowski H: Colorectal carcinoma-specific antigen: Detection by means of monoclonal antibodies. Proc Natl Acad Sci USA 76: 1438-1442, 1979.

2. Schnell U, Cirulli V and Giepmans BN: EpCAM: Structure and function in health and disease. Biochim Biophys Acta 1828: 1989-2001, 2013.

3. Balzar M, Winter MJ, De Boer CJ and Litvinov SV: The biology of the 17-1A antigen (Ep-CAM). J Mol Med (Berl) 77: 699-712, 1999.

4. Schmelzer E, Zhang L, Bruce A, Wauthier E, Ludlow J, Yao HL, Moss N, Melhem A, McClelland R, Turner W, et al: Human hepatic stem cells from fetal and postnatal donors. J Exp Med 204: 1973-1987, 2007.

5. Kamimoto K, Kaneko K, Kok CY, Okada H, Miyajima A and Itoh $\mathrm{T}$ : Heterogeneity and stochastic growth regulation of biliary epithelial cells dictate dynamic epithelial tissue remodeling. Elife 5: e15034, 2016.

6. Sivagnanam M, Mueller JL, Lee H, Chen Z, Nelson SF, Turner D, Zlotkin SH, Pencharz PB, Ngan BY, Libiger O, et al: Identification of EpCAM as the gene for congenital tufting enteropathy. Gastroenterology 135: 429-437, 2008.

7. Lei Z, Maeda T, Tamura A, Nakamura T, Yamazaki Y, Shiratori H, Yashiro K, Tsukita S and Hamada H: EpCAM contributes to formation of functional tight junction in the intestinal epithelium by recruiting claudin proteins. Dev Biol 371: 136-145, 2012.

8. Guerra E, Lattanzio R, La Sorda R, Dini F, Tiboni GM, Piantelli $M$ and Alberti S: mTrop1/Epcam knockout mice develop congenital tufting enteropathy through dysregulation of intestinal E-cadherin/ $\beta$-catenin. PLos One 7: e49302, 2012.

9. Mueller JL, McGeough MD, Peña CA and Sivagnanam M: Functional consequences of EpCam mutation in mice and men. Am J Physiol Gastrointest Liver Physiol 306: G278-G288, 2014.

10. Nagao K, Zhu J, Heneghan MB, Hanson JC, Morasso MI, Tessarollo L, Mackem S and Udey MC: Abnormal placental development and early embryonic lethality in EpCAM-null mice. PLos One 4: e8543, 2009.

11. Gaiser MR, Lämmermann T, Feng X, Igyarto BZ, Kaplan DH, Tessarollo L, Germain RN and Udey MC: Cancer-associated epithelial cell adhesion molecule (EpCAM; CD326) enables epidermal Langerhans cell motility and migration in vivo. Proc Natl Acad Sci USA 109: E889-E897, 2012.

12. Slanchev K, Carney TJ, Stemmler MP, Koschorz B, Amsterdam A, Schwarz $\mathrm{H}$ and Hammerschmidt M: The epithelial cell adhesion molecule EpCAM is required for epithelial morphogenesis and integrity during zebrafish epiboly and skin development. PLos Genet 5: e1000563, 2009.

13. Maghzal N, Vogt E, Reintsch W, Fraser JS and Fagotto F: The tumor-associated EpCAM regulates morphogenetic movements through intracellular signaling. J Cell Biol 191: 645-659, 2010.

14. Maghzal N, Kayali HA, Rohani N, Kajava AV and Fagotto F: EpCAM controls actomyosin contractility and cell adhesion by direct inhibition of PKC. Dev Cell 27: 263-277, 2013.

15. Lu H, Ma J, Yang Y, Shi W and Luo L: EpCAM is an endoderm-specific Wnt derepressor that licenses hepatic development. Dev Cell 24: 543-553, 2013.

16. Trzpis M, McLaughlin PM, De Leij LM and Harmsen MC: Epithelial cell adhesion molecule: More than a carcinoma marker and adhesion molecule. Am J Pathol 171: 386-395, 2007.

17. Cirulli V, Crisa L, Beattie GM, Mally MI, Lopez AD, Fannon A, Ptasznik A, Inverardi L, Ricordi C, Deerinck T, et al: KSA antigen Ep-CAM mediates cell-cell adhesion of pancreatic epithelial cells: Morphoregulatory roles in pancreatic islet development. J Cell Biol 140: 1519-1534, 1998.

18. Lipinski M, Parks DR, Rouse RV and Herzenberg LA: Human trophoblast cell-surface antigens defined by monoclonal antibodies. Proc Natl Acad Sci USA 78: 5147-5150, 1981.
19. Sherwood RI, Jitianu C, Cleaver O, Shaywitz DA, Lamenzo JO, Chen AE, Golub TR and Melton DA: Prospective isolation and global gene expression analysis of definitive and visceral endoderm. Dev Biol 304: 541-555, 2007.

20. Poon CE, Madawala RJ, Day ML and Murphy CR: EpCAM is decreased but is still present in uterine epithelial cells during early pregnancy in the rat: Potential mechanism for maintenance of mucosal integrity during implantation. Cell Tissue Res 359: 655-664, 2015.

21. Dalerba P, Dylla SJ, Park IK, Liu R, Wang X, Cho RW, Hoey T, Gurney A, Huang EH, Simeone DM, et al: Phenotypic characterization of human colorectal cancer stem cells. Proc Natl Acad Sci USA 104: 10158-10163, 2007.

22. Yamashita T, Ji J, Budhu A, Forgues M, Yang W, Wang HY, Jia H, Ye Q, Qin LX, Wauthier E, et al: EpCAM-positive hepatocellular carcinoma cells are tumor-initiating cells with stem/progenitor cell features. Gastroenterology 136: 1012-1024, 2009.

23. Baeuerle PA and Gires O: EpCAM (CD326) finding its role in cancer. Br J Cancer 96: 417-423, 2007.

24. Ladwein M, Pape UF, Schmidt DS, Schnölzer M, Fiedler S, Langbein L, Franke WW, Moldenhauer G and Zöller M: The cell-cell adhesion molecule EpCAM interacts directly with the tight junction protein claudin-7. Exp Cell Res 309: 345-357, 2005.

25. Maetzel D, Denzel S, Mack B, Canis M, Went P, Benk M, Kieu C, Papior P, Baeuerle PA, Munz M and Gires O: Nuclear signalling by tumour-associated antigen EpCAM. Nat Cell Biol 11: 162-171, 2009.

26. Dollé L, Theise ND, Schmelzer E, Boulter L, Gires O and van Grunsven LA: EpCAM and the biology of hepatic stem/progenitor cells. Am J Physiol Gastrointest Liver Physiol 308: G233-G250, 2015.

27. Litvinov SV, Velders MP, Bakker HA, Fleuren GJ and Warnaar SO: Ep-CAM: A human epithelial antigen is a homophilic cell-cell adhesion molecule. J Cell Biol 125: 437-446, 1994.

28. Zhang C, Liu LW, Sun WJ, Qin SH, Qin LZ and Wang X: Expressions of E-cadherin, p120ctn, $\beta$-catenin and NF- $\kappa \mathrm{B}$ in ulcerative colitis. J Huazhong Univ Sci Technolog Med Sci 35: 368-373, 2015.

29. Frixen UH, Behrens J, Sachs M, Eberle G, Voss B, Warda A, Löchner D and Birchmeier W: E-cadherin-mediated cell-cell adhesion prevents invasiveness of human carcinoma cells. J Cell Biol 113: 173-185, 1991.

30. Berx G, Nollet F and van Roy F: Dysregulation of the E-cadherin/catenin complex by irreversible mutations in human carcinomas. Cell Adhes Commun 6: 171-184, 1998.

31. Handschuh G, Candidus S, Luber B, Reich U, Schott C, Oswald S, Becke H, Hutzler P, Birchmeier W, Höfler H and Becker KF: Tumour-associated E-cadherin mutations alter cellular morphology, decrease cellular adhesion and increase cellular motility. Oncogene 18: 4301-4312, 1999.

32. Guilford P, Hopkins J, Harraway J, McLeod M, McLeod N Harawira P, Taite H, Scoular R, Miller A and Reeve AE: E-cadherin germline mutations in familial gastric cancer. Nature 392: 402-405, 1998

33. Gayther SA, Gorringe KL, Ramus SJ, Huntsman D, Roviello F, Grehan N, Machado JC, Pinto E, Seruca R, Halling K, et al: Identification of germ-line E-cadherin mutations in gastric cancer families of European origin. Cancer Res 58: 4086-4089, 1998.

34. Corso G, Marrelli D and Roviello F: Familial gastric cancer and germline mutations of E-cadherin. Ann Ital Chir 83: 177-182, 2012.

35. Litvinov SV, Balzar M, Winter MJ, Bakker HA, Briaire-De Bruijn IH, Prins F, Fleuren GJ and Warnaar SO: Epithelial cell adhesion molecule (Ep-CAM) modulates cell-cell interactions mediated by classic cadherins. J Cell Biol 139: 1337-1348, 1997.

36. Winter MJ, Nagelkerken B, Mertens AE, Rees-Bakker HA, Briaire-De Bruijn IH and Litvinov SV: Expression of Ep-CAM shifts the state of cadherin-mediated adhesions from strong to weak. Exp Cell Res 285: 50-58, 2003.

37. Kozan PA, McGeough MD, Peña CA, Mueller JL, Barrett KE, Marchelletta RR and Sivagnanam M: Mutation of EpCAM leads to intestinal barrier and ion transport dysfunction. J Mol Med (Berl) 93: 535-545, 2015.

38. Bondow BJ, Faber ML, Wojta KJ, Walker EM and Battle MA: E-cadherin is required for intestinal morphogenesis in the mouse. Dev Biol 371: 1-12, 2012. 
39. Tunggal JA, Helfrich I, Schmitz A, Schwarz H, Günzel D, Fromm M, Kemler R, Krieg T and Niessen CM: E-cadherin is essential for in vivo epidermal barrier function by regulating tight junctions. EMBO J 24: 1146-1156, 2005.

40. Patey N, Scoazec JY, Cuenod-Jabri B, Canioni D, Kedinger M, Goulet $\mathrm{O}$ and Brousse $\mathrm{N}$ : Distribution of cell adhesion molecules in infants with intestinal epithelial dysplasia (tufting enteropathy). Gastroenterology 113: 833-843, 1997.

41. Wu CJ, Mannan P, Lu M and Udey MC: Epithelial cell adhesion molecule (EpCAM) regulates claudin dynamics and tight junctions. J Biol Chem 288: 12253-12268, 2013.

42. Salomon J, Gaston C, Magescas J, Duvauchelle B, Canioni D, Sengmanivong L, Mayeux A, Michaux G, Campeotto F, Lemale J, et al: Contractile forces at tricellular contacts modulate epithelial organization and monolayer integrity. Nat Commun 8: $13998,2017$.

43. Kuhn S, Koch M, Nübel T, Ladwein M, Antolovic D, Klingbeil P, Hildebrand D, Moldenhauer G, Langbein L, Franke WW, et al: A complex of EpCAM, claudin-7, CD44 variant isoforms, and tetraspanins promotes colorectal cancer progression. Mol Cancer Res 5: 553-567, 2007.

44. Nübel T, Preobraschenski J, Tuncay H, Weiss T, Kuhn S, Ladwein M, Langbein L and Zöller M: Claudin-7 regulates EpCAM-mediated functions in tumor progression. Mol Cancer Res 7: 285-299, 2009.

45. Fujita H, Chiba H, Yokozaki H, Sakai N, Sugimoto K, Wada T, Kojima T, Yamashita T and Sawada N: Differential expression and subcellular localization of claudin-7, $-8,-12,-13$, and -15 along the mouse intestine. J Histochem Cytochem 54: 933-944, 2006.

46. Hewitt KJ, Agarwal R and Morin PJ: The claudin gene family: Expression in normal and neoplastic tissues. BMC Cancer 6: 186, 2006.

47. Ding L, Lu Z, Foreman O, Tatum R, Lu Q, Renegar R, Cao J and Chen $\mathrm{YH}$ : Inflammation and disruption of the mucosal architecture in claudin-7-deficient mice. Gastroenterology 142: 305-315, 2012

48. Nakatsukasa M, Kawasaki S, Yamasaki K, Fukuoka H, Matsuda A, Tsujikawa M, Tanioka H, Nagata-Takaoka M Hamuro $\mathbf{J}$ and Kinoshita S: Tumor-associated calcium signal transducer 2 is required for the proper subcellular localization of claudin 1 and 7: Implications in the pathogenesis of gelatinous drop-like corneal dystrophy. Am J Pathol 177: 1344-1355, 2010.

49. Daugherty BL, Ward C, Smith T, Ritzenthaler JD and Koval M: Regulation of heterotypic claudin compatibility. J Biol Chem 282 30005-30013, 2007

50. Furuse M, Sasaki $\mathrm{H}$ and Tsukita S: Manner of interaction of heterogeneous claudin species within and between tight junction strands. J Cell Biol 147: 891-903, 1999.

51. Piontek J, Winkler L, Wolburg H, Müller SL, Zuleger N, Piehl C, Wiesner B, Krause G and Blasig IE: Formation of tight junction: Determinants of homophilic interaction between classic claudins. FASEB J 22: 146-158, 2008.

52. Tatum R, Zhang Y, Salleng K, Lu Z, Lin JJ, Lu Q, Jeansonne BG, Ding L and Chen YH: Renal salt wasting and chronic dehydration in claudin-7-deficient mice. Am J Physiol Renal Physiol 298: F24-F34, 2010

53. Gladden AB, Hebert AM, Schneeberger EE and McClatchey AI: The NF2 tumor suppressor, Merlin, regulates epidermal development through the establishment of a junctional polarity complex. Dev Cell 19: 727-739, 2010.

54. Tinkle CL, Pasolli HA, Stokes N and Fuchs E: New insights into cadherin function in epidermal sheet formation and maintenance of tissue integrity. Proc Natl Acad Sci USA 105: 15405-15410, 2008.

55. Vasioukhin V, Bauer C, Degenstein L, Wise B and Fuchs E Hyperproliferation and defects in epithelial polarity upon conditional ablation of alpha-catenin in skin. Cell 104: 605-617, 2001.

56. Shin K, Fogg VC and Margolis B: Tight junctions and cell polarity. Annu Rev Cell Dev Biol 22: 207-235, 2006.

57. Tepass U: Claudin complexities at the apical junctional complex. Nat Cell Biol 5: 595-597, 2003.

58. Van Campenhout CA, Eitelhuber A, Gloeckner CJ, Giallonardo P, Gegg M, Oller H, Grant SG, Krappmann D, Ueffing $M$ and Lickert $\mathrm{H}$ : Dlg3 trafficking and apical tight junction formation is regulated by nedd4 and nedd4-2 e3 ubiquitin ligases. Dev Cell 21: 479-491, 2011.

59. Goulet O, Kedinger M, Brousse N, Cuenod B, Colomb V, Patey N, De Potter S, Mougenot JF, Canioni D, Cerf-Bensussan N, et al: Intractable diarrhea of infancy with epithelial and basement membrane abnormalities. J Pediatr 127: 212-219, 1995.
60. Goulet O, Salomon J, Ruemmele F, De Serres NP and Brousse N: Intestinal epithelial dysplasia (tufting enteropathy). Orphanet $\mathrm{J}$ Rare Dis 2: 20, 2007.

61. Beaulieu JF: Differential expression of the VLA family of integrins along the crypt-villus axis in the human small intestine. J Cell Sci 102: 427-436, 1992.

62. Simon-Assmann P, Bouziges F, Vigny M and Kedinger M: Origin and deposition of basement membrane heparan sulfate proteoglycan in the developing intestine. J Cell Biol 109: 1837-1848, 1989.

63. Simon-Assmann P, Duclos B, Orian-Rousseau V, Arnold C, Mathelin C, Engvall E and Kedinger M: Differential expression of laminin isoforms and alpha 6-beta 4 integrin subunits in the developing human and mouse intestine. Dev Dyn 201: 71-85, 1994.

64. Simon-Assmann P and Kedinger M: Heterotypic cellular cooperation in gut morphogenesis and differentiation. Semin Cell Biol 4: 221-230, 1993.

65. Simo P, Simon-Assmann P, Bouziges F, Leberquier C, Kedinger M, Ekblom $P$ and Sorokin L: Changes in the expression of laminin during intestinal development. Development 112: 477-487, 1991.

66. Simo P, Bouziges F, Lissitzky JC, Sorokin L, Kedinger M and Simon-Assmann P: Dual and asynchronous deposition of laminin chains at the epithelial-mesenchymal interface in the gut. Gastroenterology 102: 1835-1845, 1992.

67. Tamura A, Hayashi H, Imasato M, Yamazaki Y, Hagiwara A Wada M, Noda T, Watanabe M, Suzuki Y and Tsukita S: Loss of claudin-15, but not claudin-2, causes $\mathrm{Na}^{+}$deficiency and glucose malabsorption in mouse small intestine. Gastroenterology 140: 913-923, 2011

68. Yáñez-Mó M, Siljander PR, Andreu Z, Zavec AB, Borràs FE, Buzas EI, Buzas K, Casal E, Cappello F, Carvalho J, et al: Biological properties of extracellular vesicles and their physiological functions. J Extracell Vesicles 4: 27066, 2015.

69. Colombo M, Raposo G and Théry C: Biogenesis, secretion, and intercellular interactions of exosomes and other extracellular vesicles. Annu Rev Cell Dev Biol 30: 255-289, 2014.

70. Tkach $\mathrm{M}$ and Théry C: Communication by extracellular vesicles: Where we are and where we need to go. Cell 164: 1226-1232, 2016.

71. Iwai S, Kurosu S, Sasaki H, Kato K and Maekawa T: Trapping and proliferation of target cells on C60 fullerene nano fibres. Heliyon 3: e00386, 2017.

72. Jiang L, Shen Y, Guo D, Yang D, Liu J, Fei X, Yang Y, Zhang B, Lin Z, Yang F, et al: Corrigendum: EpCAM-dependent extracellular vesicles from intestinal epithelial cells maintain intestinal tract immune balance. Nat Commun 8: 16006, 2017.

73. Cai Z, Zhang W, Yang F, Yu L, Yu Z, Pan J, Wang L, Cao X and Wang J: Immunosuppressive exosomes from TGF- $\beta 1$ gene-modified dendritic cells attenuate Th17-mediated inflammatory autoimmune disease by inducing regulatory T cells. Cell Res 22: 607-610, 2012

74. Yu L, Yang F, Jiang L, Chen Y, Wang K, Xu F, Wei Y, Cao X, Wang $J$ and Cai $Z$ : Exosomes with membrane-associated TGF- $\beta 1$ from gene-modified dendritic cells inhibit murine EAE independently of MHC restriction. Eur J Immunol 43: 2461-2472, 2013

75. Villablanca EJ, Renucci A, Sapède D, Lec V, Soubiran F, Sandoval PC, Dambly-Chaudière C, Ghysen A and Allende ML: Control of cell migration in the zebrafish lateral line: Implication of the gene 'tumour-associated calcium signal transducer,' tacstd. Dev Dyn 235: 1578-1588, 2006.

76. Aman A and Piotrowski T: Wnt/beta-catenin and Fgf signaling control collective cell migration by restricting chemokine receptor expression. Dev Cell 15: 749-761, 2008.

77. Sarrach S, Huang Y, Niedermeyer S, Hachmeister M, Fischer L, Gille S, Pan M, Mack B, Kranz G, Libl D, et al: Spatiotemporal patterning of EpCAM is important for murine embryonic endoand mesodermal differentiation. Sci Rep 8: 1801, 2018.

78. De Boer CJ, Van Krieken JH, Janssen-Van Rhijn CM and Litvinov SV: Expression of Ep-CAM in normal, regenerating, metaplastic, and neoplastic liver. J Pathol 188: 201-206, 1999.

79. Münz M, Kieu C, Mack B, Schmitt B, Zeidler R and Gires O: The carcinoma-associated antigen EpCAM upregulates c-myc and induces cell proliferation. Oncogene 23: 5748-5758, 2004.

80. Osta WA, Chen Y, Mikhitarian K, Mitas M, Salem M, Hannun YA, Cole DJ and Gillanders WE: EpCAM is overexpressed in breast cancer and is a potential target for breast cancer gene therapy. Cancer Res 64: 5818-5824, 2004. 
81. Schmelzer E, Wauthier E and Reid LM: The phenotypes of pluripotent human hepatic progenitors. Stem Cells 24: 1852-1858, 2006.

82.Zhang L, Theise N, Chua M and Reid LM: The stem cell niche of human livers: Symmetry between development and regeneration. Hepatology 48: 1598-1607, 2008.

83. Shimazaki T, Okazawa H, Fujii H, Ikeda M, Tamai K, McKay RD, Muramatsu M and Hamada H: Hybrid cell extinction and re-expression of Oct-3 function correlates with differentiation potential. EMBO J 12: 4489-4498, 1993.

84. González B, Denzel S, Mack B, Conrad M and Gires O: EpCAM is involved in maintenance of the murine embryonic stem cell phenotype. Stem Cells 27: 1782-1791, 2009.

85. Lu TY, Lu RM, Liao MY, Yu J, Chung CH, Kao CF and Wu HC: Epithelial cell adhesion molecule regulation is associated with the maintenance of the undifferentiated phenotype of human embryonic stem cells. J Biol Chem 285: 8719-8732, 2010.

86. Okabe M, Tsukahara Y, Tanaka M, Suzuki K, Saito S, Kamiya Y, Tsujimura T, Nakamura K and Miyajima A: Potential hepatic stem cells reside in $\mathrm{EpCAM}^{+}$cells of normal and injured mouse liver. Development 136: 1951-1960, 2009.

87. Tanaka M, Okabe M, Suzuki K, Kamiya Y, Tsukahara Y, Saito S and Miyajima A: Mouse hepatoblasts at distinct developmental stages are characterized by expression of EpCAM and DLK1: Drastic change of EpCAM expression during liver development. Mech Dev 126: 665-676, 2009.

88. Hachmeister M, Bobowski KD, Hogl S, Dislich B, Fukumori A, Eggert C, Mack B, Kremling H, Sarrach S, Coscia F, et al: Regulated intramembrane proteolysis and degradation of murine epithelial cell adhesion molecule mEpCAM. PLos One 8: e71836, 2013.

89. Huang HP, Chen PH, Yu CY, Chuang CY, Stone L, Hsiao WC, Li CL, Tsai SC, Chen KY, Chen HF, et al: Epithelial cell adhesion molecule (EpCAM) complex proteins promote transcription factor-mediated pluripotency reprogramming. J Biol Chem 286: 33520-33532, 2011.

90. Yu T, Ma Y and Wang H: EpCAM intracellular domain promotes porcine cell reprogramming by upregulation of pluripotent gene expression via beta-catenin signaling. Sci Rep 7: 46315, 2017.

91.Kuan II, Liang KH, Wang YP, Kuo TW, Meir YJ, Wu SC, Yang SC, Lu J and Wu HC: EpEX/EpCAM and Oct4 or Klf4 alone are sufficient to generate induced pluripotent stem cells through STAT3 and HIF2 $\alpha$. Sci Rep 7: 41852, 2017.

92. Salomon J, Goulet O, Canioni D, Brousse N, Lemale J, Tounian P, Coulomb A, Marinier E, Hugot JP, Ruemmele F, et al: Genetic characterization of congenital tufting enteropathy: Epcam associated phenotype and involvement of SPINT2 in the syndromic form. Hum Genet 133: 299-310, 2014

93. Slae MA, Saginur M, Persad R, Yap J, Lacson A, Salomon J, Canioni D and Huynh HQ: Syndromic congenital diarrhea because of the SPINT2 mutation showing enterocyte tufting and unique electron microscopy findings. Clin Dysmorphol 22 118-120, 2013

94.Furuse M, Furuse K, Sasaki H and Tsukita S: Conversion of zonulae occludentes from tight to leaky strand type by introducing claudin-2 into Madin-Darby canine kidney I cells. J Cell Biol 153: 263-272, 2001

95. Van Itallie CM, Fanning AS and Anderson JM: Reversal of charge selectivity in cation or anion-selective epithelial lines by expression of different claudins. Am J Physiol Renal Physiol 285: F1078-F1084, 2003.

96. Hou J, Gomes AS, Paul DL and Goodenough DA: Study of claudin function by RNA interference. J Biol Chem 281: 36117-36123, 2006.

97. Amasheh S, Meiri N, Gitter AH, Schöneberg T, Mankertz J, Schulzke JD and Fromm M: Claudin-2 expression induces cation-selective channels in tight junctions of epithelial cells. J Cell Sci 115: 4969-4976, 2002.

98. Yu AS, Cheng MH, Angelow S, Günzel D, Kanzawa SA, Schneeberger EE, Fromm M and Coalson RD: Molecular basis for cation selectivity in claudin-2-based paracellular pores: Identification of an electrostatic interaction site. J Gen Physiol 133: 111-127, 2009.

99. Schultz SG and Curran PF: Coupled transport of sodium and organic solutes. Physiol Rev 50: 637-718, 1970.

100. Kapus A and Szászi K: Coupling between apical and paracellular transport processes. Biochem Cell Biol 84: 870-880, 2006.
101. Tsukaguchi H, Tokui T, Mackenzie B, Berger UV, Chen XZ, Wang Y, Brubaker RF and Hediger MA: A family of mammalian $\mathrm{Na}^{+}$-dependent L-ascorbic acid transporters. Nature 399: 70-75, 1999.

102. Holmes JL, Van Itallie CM, Rasmussen JE and Anderson JM: Claudin profiling in the mouse during postnatal intestinal development and along the gastrointestinal tract reveals complex expression patterns. Gene Expr Patterns 6: 581-588, 2006.

103. Wada M, Tamura A, Takahashi N and Tsukita S: Loss of claudins 2 and 15 from mice causes defects in paracellular $\mathrm{Na}^{+}$flow and nutrient transport in gut and leads to death from malnutrition. Gastroenterology 144: 369-380, 2013.

104.Zhou N, Wang H, Liu H, Xue H, Lin F, Meng X, Liang A, Zhao Z, Liu Y and Qian H: MTA1-upregulated EpCAM is associated with metastatic behaviors and poor prognosis in lung cancer. J Exp Clin Cancer Res 34: 157, 2015.

105.Zheng X, Fan X, Fu B, Zheng M, Zhang A, Zhong K, Yan J, Sun R, Tian Z and Wei H: EpCAM inhibition sensitizes chemoresistant leukemia to immune surveillance. Cancer Res 77: 482-493, 2017.

106. Patriarca C, Macchi RM, Marschner AK and Mellstedt H: Epithelial cell adhesion molecule expression (CD326) in cancer: A short review. Cancer Treat Rev 38: 68-75, 2012.

107. Wang MH, Sun R, Zhou XM, Zhang MY, Lu JB, Yang Y, Zeng LS, Yang XZ, Shi L, Xiao RW, et al: Epithelial cell adhesion molecule overexpression regulates epithelial-mesenchymal transition, stemness and metastasis of nasopharyngeal carcinoma cells via the PTEN/AKT/mTOR pathway. Cell Death Dis 9: 2, 2018.

108. Denzel S, Maetzel D, Mack B, Eggert C, Bärr G and Gires O: Initial activation of EpCAM cleavage via cell-to-cell contact. BMC Cancer 9: 402, 2009.

109. Xiang D, Shigdar S, Bean AG, Bruce M, Yang W, Mathesh M, Wang $\mathrm{T}$, Yin W, Tran $\mathrm{PH}, \mathrm{Al}$ Shamaileh $\mathrm{H}$, et al: Transforming doxorubicin into a cancer stem cell killer via EpCAM aptamer-mediated delivery. Theranostics 7: 4071-4086, 2017

110. Hoe SLL, Tan LP, Abdul Aziz N, Liew K, Teow SY, Abdul Razak FR, Chin YM, Mohamed Shahrehan NA, Chu TL, Mohd Kornain NK, et al: CD24, CD44 and EpCAM enrich for tumour-initiating cells in a newly established patient-derived xenograft of nasopharyngeal carcinoma. Sci Rep 7: 12372, 2017.

111. Choi YJ, Park SJ, Park YS, Park HS, Yang KM and Heo K: EpCAM peptide-primed dendritic cell vaccination confers significant anti-tumor immunity in hepatocellular carcinoma cells. PLos One 13: e0190638, 2018.

112. Hwang EY, Yu CH, Cheng SJ, Chang JY, Chen HM and Chiang CP: Decreased expression of Ep-CAM protein is significantly associated with the progression and prognosis of oral squamous cell carcinomas in Taiwan. J Oral Pathol Med 38: 87-93, 2009.

113. Gosens MJ, Van Kempen LC, Van de Velde CJ, Van Krieken JH and Nagtegaal ID: Loss of membranous Ep-CAM in budding colorectal carcinoma cells. Mod Pathol 20: 221-232, 2007.

114. Wen KC, Sung PL, Chou YT, Pan CM, Wang PH, Lee OK and $\mathrm{Wu} \mathrm{CW}$ : The role of EpCAM in tumor progression and the clinical prognosis of endometrial carcinoma. Gynecol Oncol 148: 383-392, 2018

115. Maloy KJ and Powrie F: Intestinal homeostasis and its breakdown in inflammatory bowel disease. Nature 474: 298-306, 2011.

116. Kaser A, Zeissig S and Blumberg RS: Inflammatory bowel disease. Annu Rev Immunol 28: 573-621, 2010.

117. Mankertz J and Schulzke JD: Altered permeability in inflammatory bowel disease: Pathophysiology and clinical implications. Curr Opin Gastroenterol 23: 379-383, 2007.

118. Welcker K, Martin A, Kölle P, Siebeck M and Gross M: Increased intestinal permeability in patients with inflammatory bowel disease. Eur J Med Res 9: 456-460, 2004.

119. Doğan A, Wang ZD and Spencer J: E-cadherin expression in intestinal epithelium. J Clin Pathol 48: 143-146, 1995.

120. Gassler N, Rohr C, Schneider A, Kartenbeck J, Bach A, Obermüller N, Otto HF and Autschbach F: Inflammatory bowel disease is associated with changes of enterocytic junctions. Am J Physiol Gastrointest Liver Physiol 281: G216-G228, 2001.

121.Jankowski JA, Bedford FK, Boulton RA, Cruickshank N, Hall C, Elder J, Allan R, Forbes A, Kim YS, Wright NA and Sanders DS: Alterations in classical cadherins associated with progression in ulcerative and Crohn's colitis. Lab Invest 78: 1155-1167, 1998. 
122.Karayiannakis AJ, Syrigos KN, Efstathiou J, Valizadeh A, Noda M, Playford RJ, Kmiot W and Pignatelli M: Expression of catenins and E-cadherin during epithelial restitution in inflammatory bowel disease. J Pathol 185: 413-418, 1998.

123. Kucharzik T, Walsh SV, Chen J, Parkos CA and Nusrat A: Neutrophil transmigration in inflammatory bowel disease is associated with differential expression of epithelial intercellular junction proteins. Am J Pathol 159: 2001-2009, 2001.

124. Jiang L, Shen Y, Guo D, Yang D, Liu J, Fei X, Yang Y, Zhang B, Lin Z, Yang F, et al: EpCAM-dependent extracellular vesicles from intestinal epithelial cells maintain intestinal tract immune balance. Nat Commun 7: 13045, 2016.

125. Tanaka H, Takechi M, Kiyonari H, Shioi G, Tamura A and Tsukita S: Intestinal deletion of Claudin-7 enhances paracellular organic solute flux and initiates colonic inflammation in mice. Gut 64: 1529-1538, 2015.

126. Sherman PM, Mitchell DJ and Cutz E: Neonatal enteropathies: Defining the causes of protracted diarrhea of infancy. J Pediatr Gastroenterol Nutr 38: 16-26, 2004.

127. Ranganathan S, Schmitt LA and Sindhi R: Tufting enteropathy revisited: The utility of MOC31 (EpCAM) immunohistochemistry in diagnosis. Am J Surg Pathol 38: 265-272, 2014.

128. Khounlotham M, Kim W, Peatman E, Nava P, MedinaContreras O, Addis C, Koch S, Fournier B, Nusrat A Denning TL and Parkos CA: Compromised intestinal epithelial barrier induces adaptive immune compensation that protects from colitis. Immunity 37: 563-573, 2012.

129. Song Y, Liu C, Liu X, Trottier J, Beaudoin M, Zhang L, Pope C, Peng G, Barbier O,Zhong X, et al: H19 promotes cholestatic liver fibrosis by preventing ZEB1-mediated inhibition of epithelial cell adhesion molecule. Hepatology 66: 1183-1196, 2017.
130.Zen Y, Vara R, Portmann B and Hadzic N: Childhood hepatocellular carcinoma: A clinicopathological study of 12 cases with special reference to EpCAM. Histopathology 64: 671-682, 2014.

131. Ueno M, Lee LK, Chhabra A, Kim YJ, Sasidharan R, Van Handel B, Wang Y, Kamata M, Kamran P, Sereti KI, et al: c-Met-dependent multipotent labyrinth trophoblast progenitors establish placental exchange interface. Dev Cell 27: 373-386, 2013.

132. Nakaya Y and Sheng G: EMT in developmental morphogenesis. Cancer Lett 341: 9-15, 2013.

133. Han Y, Mu Y, Li X, Xu P, Tong J, Liu Z, Ma T, Zeng G, Yang S, Du J and Meng A: Grhl2 deficiency impairs otic development and hearing ability in a zebrafish model of the progressive dominant hearing loss DFNA28. Hum Mol Genet 20: 3213-3226, 2011.

134. Al-Mayouf SM, Alswaied N, Alkuraya FS, Almehaidib A and Faqih M: Tufting enteropathy and chronic arthritis: A newly recognized association with a novel EpCAM gene mutation. J Pediatr Gastroenterol Nutr 49: 642-644, 2009.

135. Bird LM, Sivagnanam M, Taylor S and Newbury RO: A new syndrome of tufting enteropathy and choanal atresia, with ophthalmologic, hematologic and hair abnormalities. Clin Dysmorphol 16: 211-221, 2007.

This work is licensed under a Creative Commons Attribution-NonCommercial-NoDerivatives 4.0 International (CC BY-NC-ND 4.0) License. 